\title{
Adolescencia femenina y ritual. La celebración de las quinceañeras enalgunas comunidades en México
}

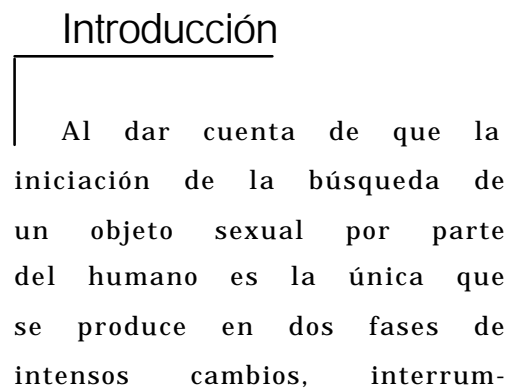

Eldesamollo sexual humano, a diferencia del deotras especies, se da en dos fases, la segunda delas cuales, llamadaadolescencia, se caracteriza por un gran incremento de los impulsos sexuales yagresivos yuna especial flexibilidad que permite reacomodos de la subjetividad para su integracióna la vida adulta. La adolescencia representa unreto para las diversas comunidades que buscan, cada una asu manera, encauzarla energía delas ylos nacientes adultos a fin de que se invierta en formas queno amenacen el equilibrio social, pero algunas de las ofertas culturales hechas a las y los adolescentes limitan también su potencial de desarrolloy creatividad. Enel presenteartículo, la autora rastrea los significados de la fiesta de 15años conla quese celebra exclusivamente a mujeres en algunas comunidades mexicanas ysepregunta porlosmensajes que tal fiesta intenta hacer llegar a la niña que se vuelve mujer, así como por los posibles beneficios y limitaciones queella representa.

$\downarrow$ Profesoralnvestigadora delDepartamento deEstudios en Educación emmaniz0808@hotmail.com pidas por un periodo de relativa estabilidad, en el cual los impulsos sexuales se atemperan (y las niñas y los niños tienden a dedicar buena parte de su energía al aprendizaje de habilidades y destrezas), Freud señala una de las características que hacen del humano un ser especialmente flexible y creativo, convirtiendo a nuestra especie en la única, hasta hoy día, capaz de adaptar el medio a sus necesidades produciendo cultura. En “Tres Ensayos para una Teoría Sexual" comenta Freud en relación a las dos fases de avance del desarrollo sexual marcadas por la búsqueda de los primeros objetos amorosos: “El primer impulso se inicia entre los dos $y$ cinco años $y$ se detiene o involuciona durante el periodo de latencia: se caracteriza por la naturaleza infantil de sus metas sexuales. El segundo arranca con la pubertad y 


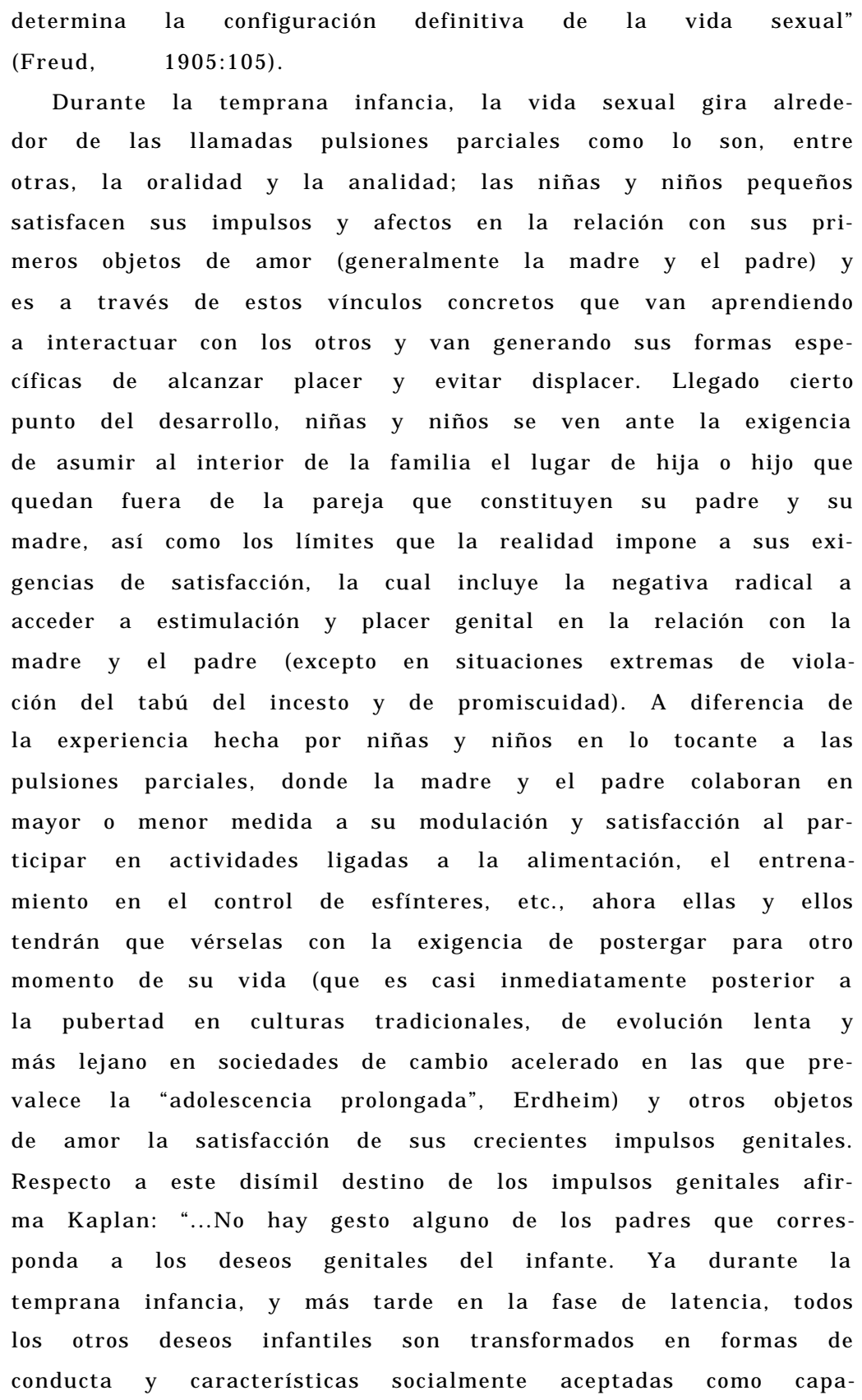




\section{Adolescencia femenina yritual}

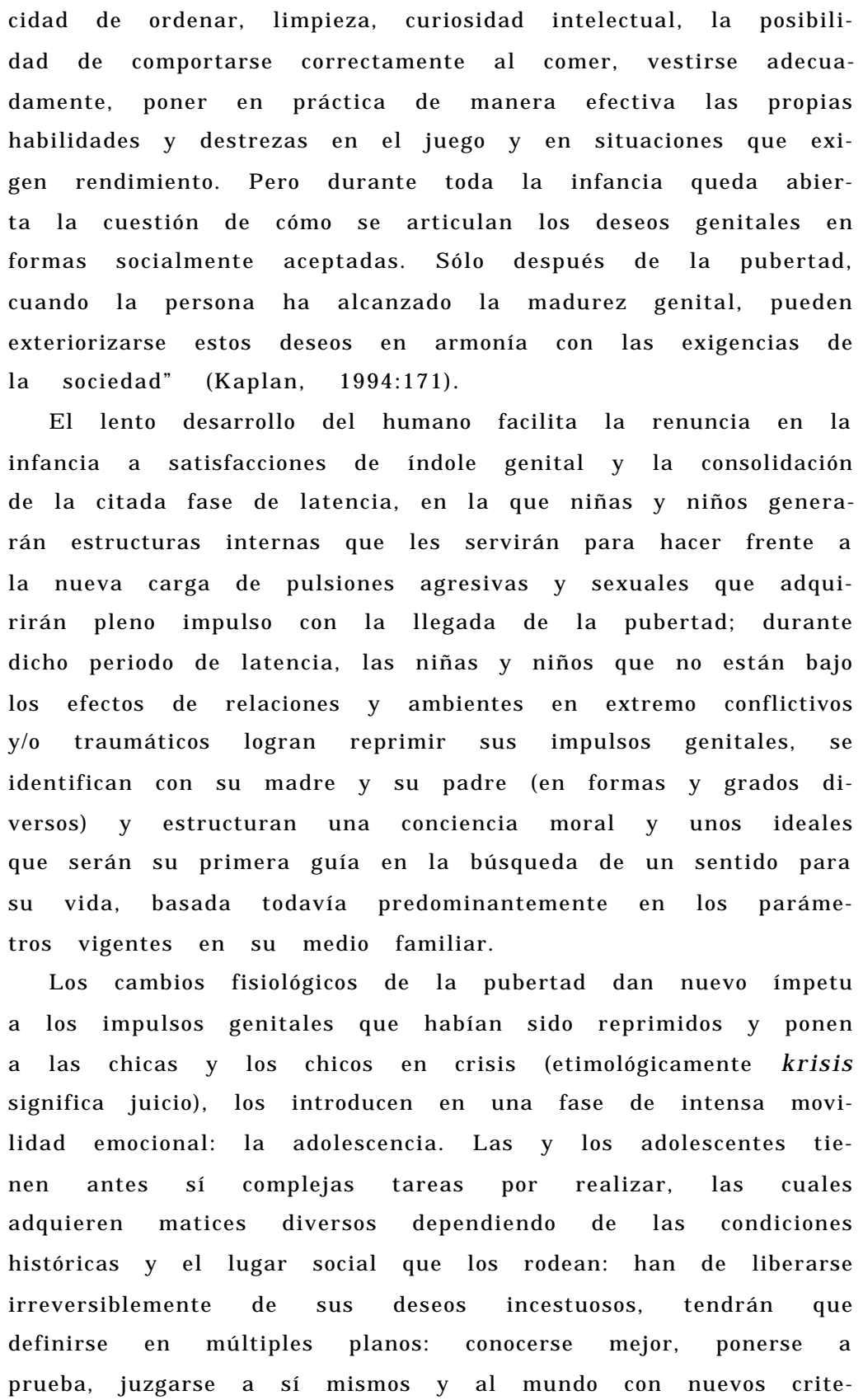


rios, tomar distancia del núcleo familiar, encontrar su sitio en el mundo de los adultos al que pretenden ingresar. En la adolescencia se vuelve patente la correlación de los procesos corporales con la vida anímica y con la realidad sociocultural de los individuos.

\section{La adolescencia en culturas deevolución lenta y en culturas de cambio acelerado}

La adolescencia es privilegio de la especie humana y ha
sido frecuentemente descrita como una "segunda oportuni-
dad" para la reestructuración de la personalidad y la resolu-
ción de conflictos fundamentales; es una fase experimental
en la que las y los jóvenes están a la búsqueda del acomodo
más creativo posible para ellos en su medio social y son a la
vez sujetos que pueden producir cambio cultural, pues el
irrumpir de su sexualidad flexibiliza las estructuras psíqui-
cas que habían gestado en la relación con su familia y posibi-
lita el desarrollo de nuevas formas de interacción con la
comunidad.
La adolescencia, como etapa de intensos cambios para las
y los jóvenes, tiene su correlato en la vida de sus madres, sus
padres y otros adultos que interactúan con ellos, quienes son
sacudidos por la transformación de los nacientes adultos, así
como de sus formas de relación. La adolescencia implica po-
tencialmente un conflicto generacional y abre las puertas al
cuestionamiento por parte de las y los jóvenes de las exigen-
cias y costumbres de su comunidad; además de los recursos
personales que cada individuo pone en juego para buscar
arreglos creativos a las nuevas situaciones que la adolescen-
cia genera, cada cultura ofrece medios para intentar ligar la
energía de las y los adolescentes a las formas de vida y los
lugares sociales que ella les propone. Las fuerzas vitales del
crecimiento que transforman a una niña o niño en un ser
potente, sexual, capaz de reproducirse, son un torrente de




\section{Adolescencia femenina yritual}

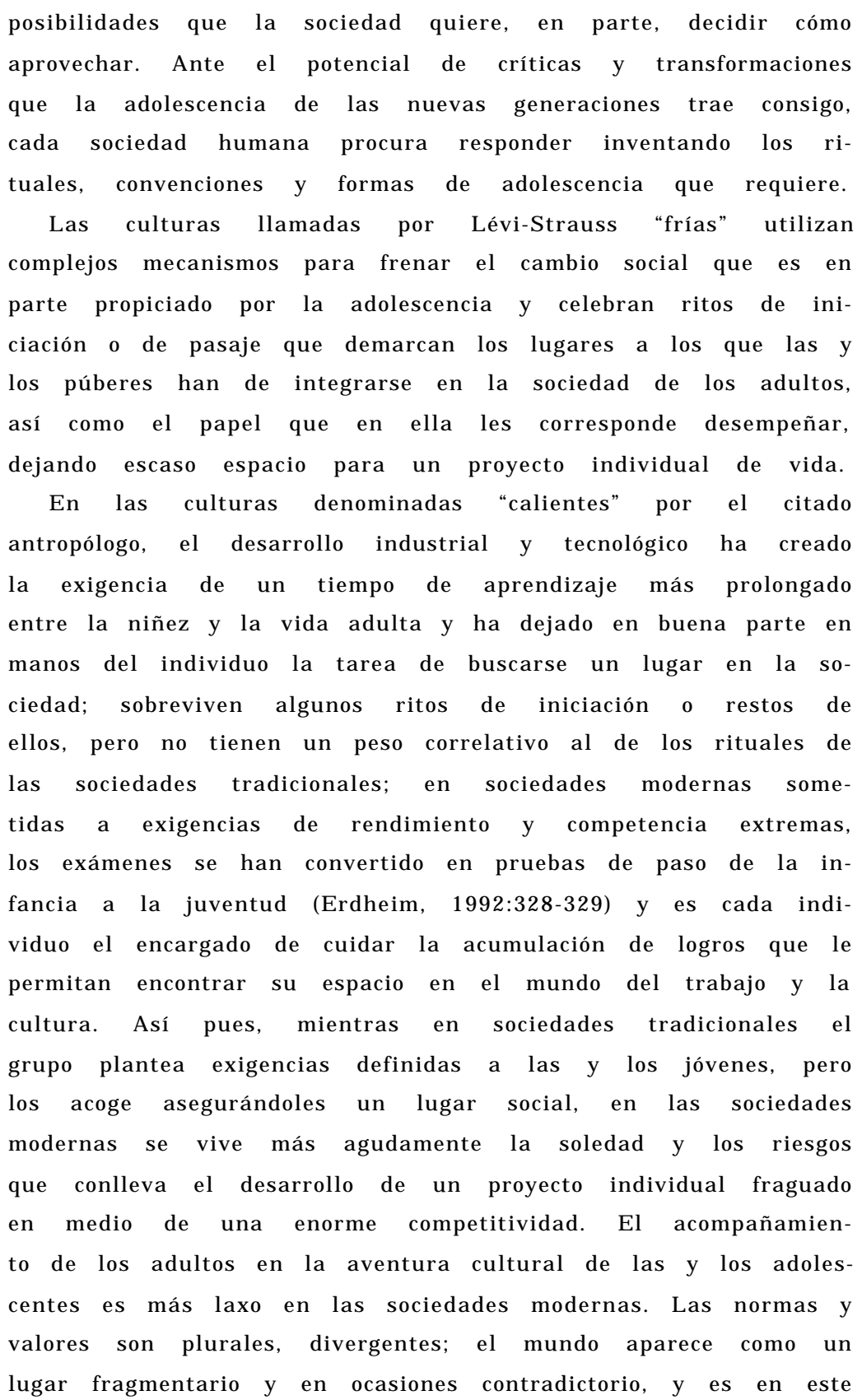


contexto donde la joven y el joven tienen que buscar un sentido a su vida; ellos llegan a la madurez sexual sin garantía alguna del lugar que habrán de ocupar entre los mayores y entre sus coetáneos.

Las culturas que Lévi-Strauss llama "frías" y "calientes" se ubican en los extremos de un continuo con todas las mezclas posibles: toda sociedad (máxime en la actualidad) tiene ámbitos con diversas "temperaturas" y en correlación con ellos se dan costumbres, rituales y fiestas con matices y características diversas.

\section{Rituales de iniciaciónysubjetividad}

Los rituales de iniciación o de pasaje son ofertas hechas a
las y los púberes por una comunidad determinada para in-
tentar encauzar el incremento de las pulsiones sexuales por
vías socialmente aceptadas y pueden considerarse desde dos
vertientes: como mensaje cultural; esto es, como el cúmulo de
símbolos, propuestas y mensajes que una cultura pretende
hacer llegar a los individuos y desde la recepción subjetiva
que cada adolescente hace de ellos.
Ya Freud en "El Malestar en la Cultura" daba cuenta de
las altas renuncias que la cultura exige a los individuos. Las
demandas y límites que una sociedad impone a los sujetos
que la integran se expresan a través de expectativas de gru-
pos de referencia, de las instituciones sociales, de la acepta-
ción o el rechazo del individuo por parte de la comunidad. Si
el desarrollo sexual de las y los adolescentes implica un im-
portante incremento de su potencial de autonomía, la socie-
dad opera poniendo freno a la satisfacción de sus deseos
sexuales, indicándoles las vías por las que tal satisfacción es
bendecida, permitida o al menos tolerada. Las demandas so-
ciales, por otra parte, no llevan en sí mismas la garantía de
la aceptación y cumplimiento por parte de los individuos que
integran la comunidad; y es precisamente del encuentro de




\section{Adolescencia femenina yritual}

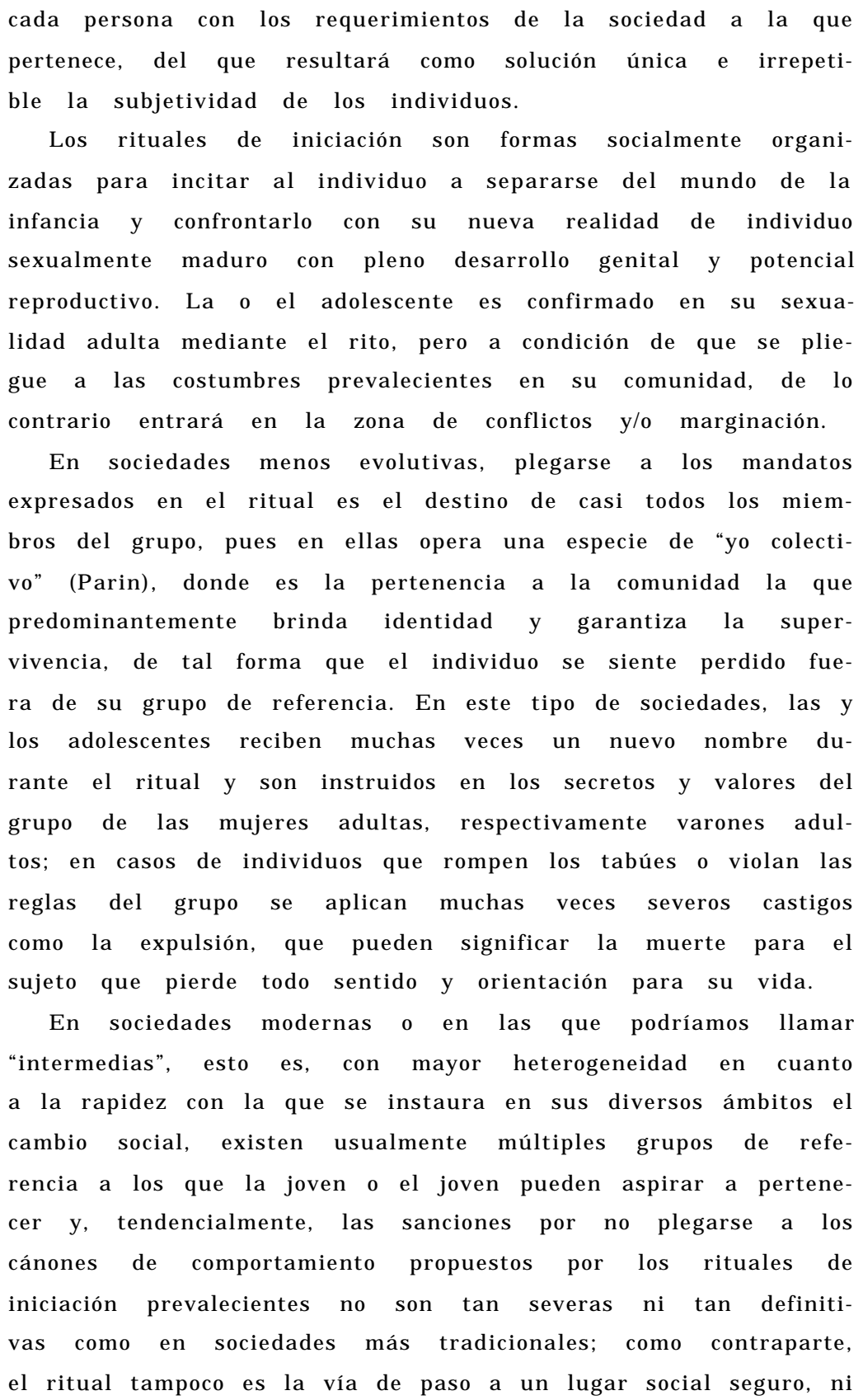




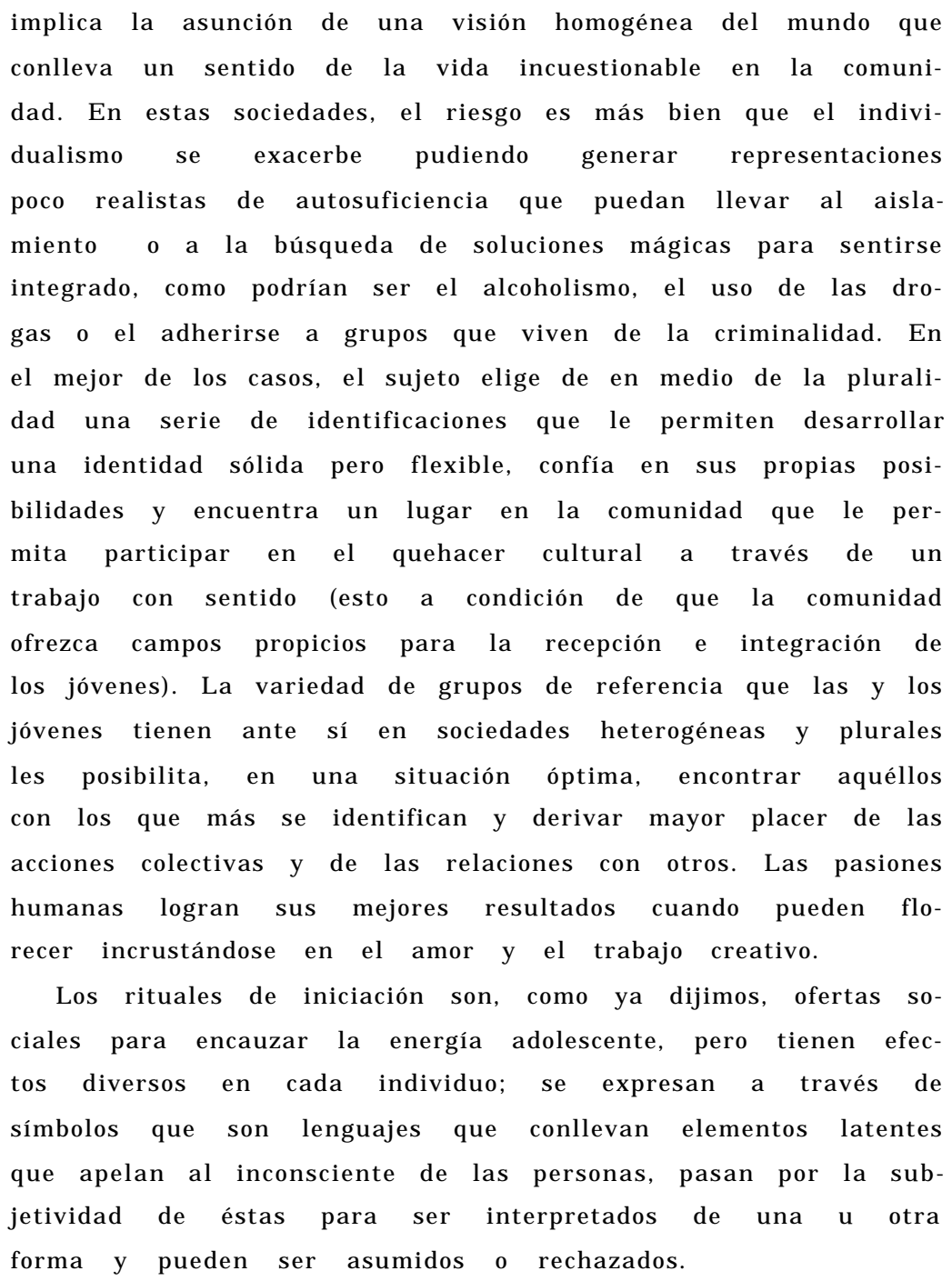

\section{Adolescencia femenina y modemidad}

Las condiciones históricas en las que ocurre la adolescencia femenina se han transformado profundamente. Mientras que a raíz de la aparición de las universidades y posterior- 


\section{Adolescencia femenina yritual}

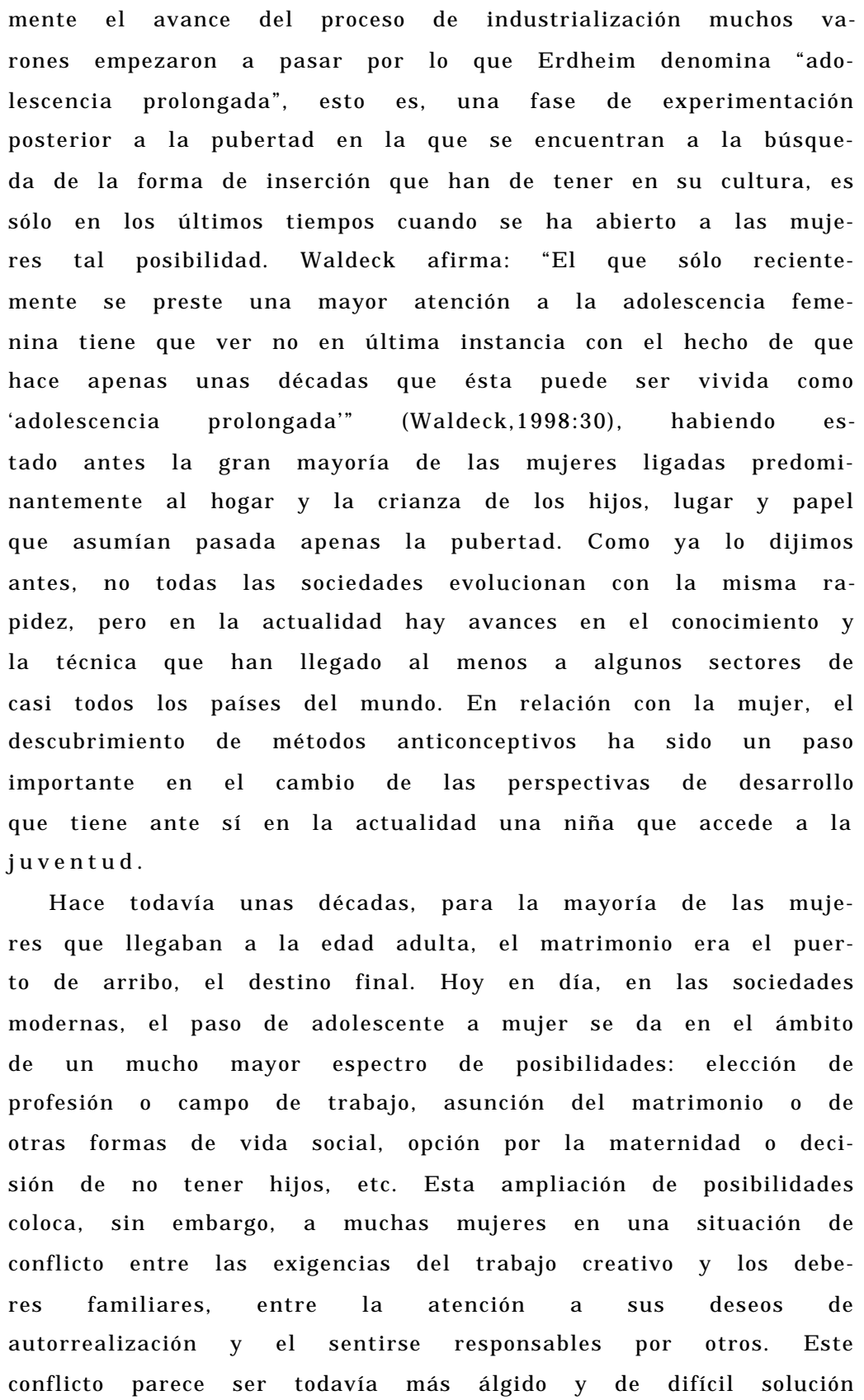

Sociedad $\$ No. 20 


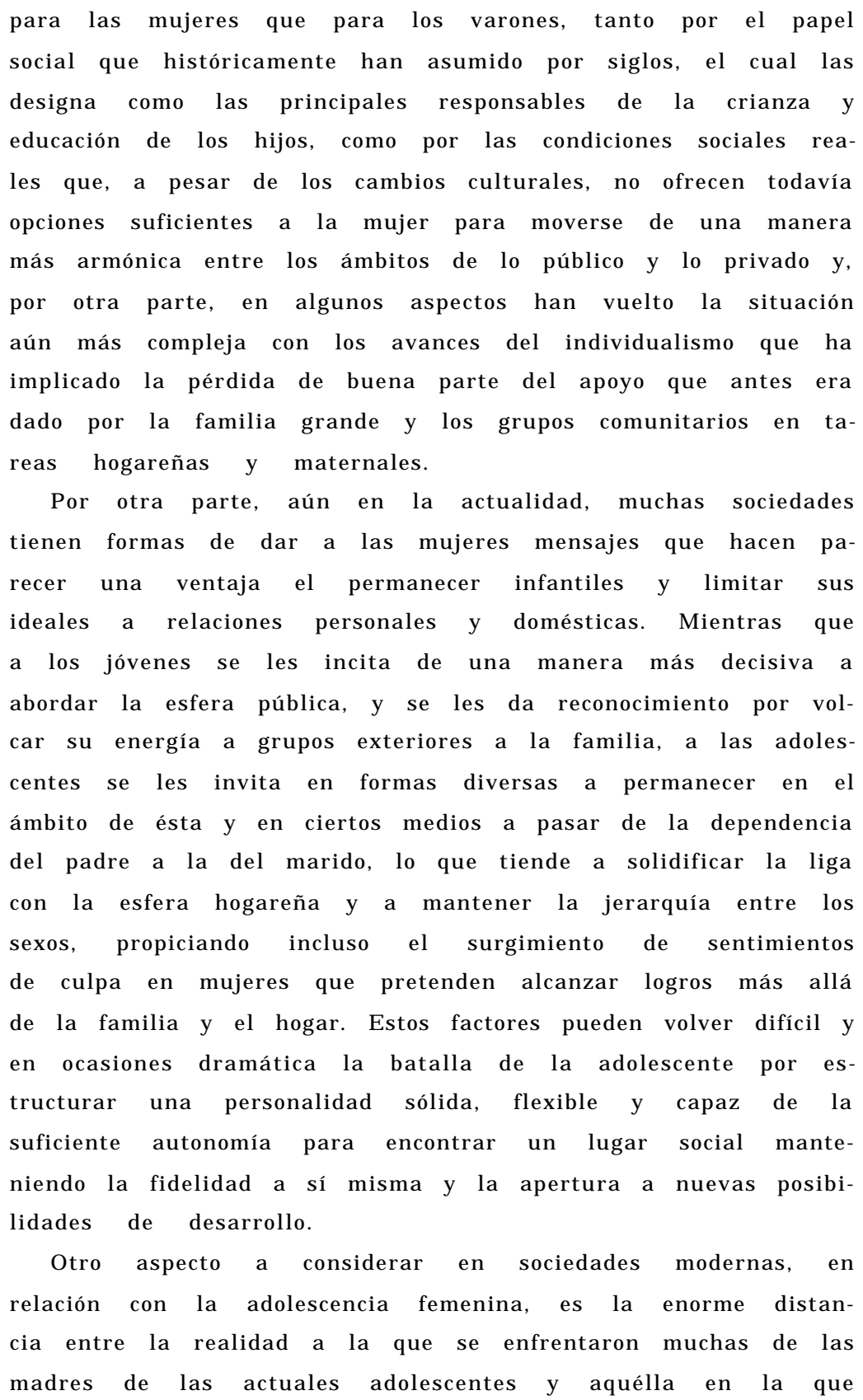




\section{Adolescencia femenina yritual}

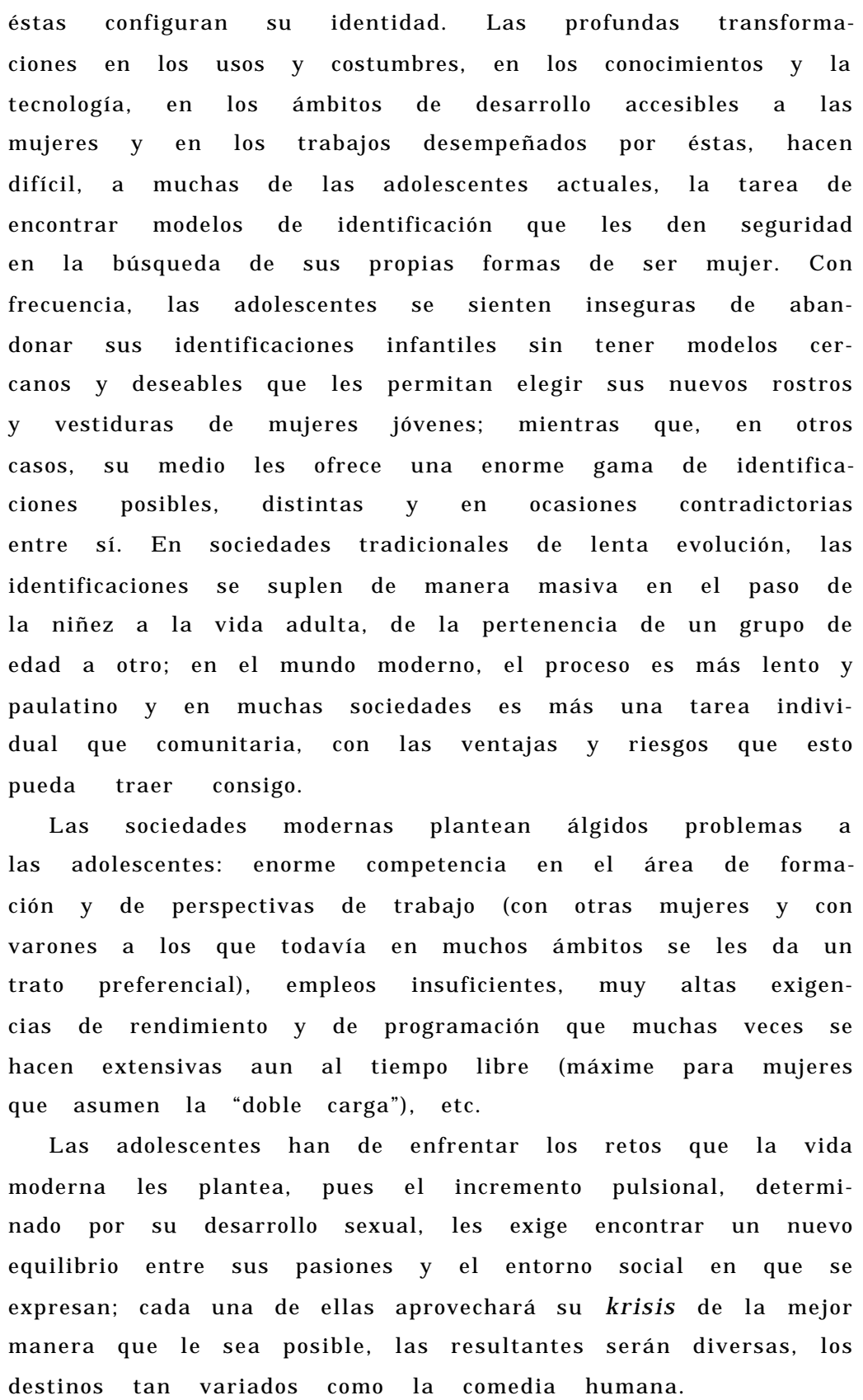




\section{Adolescenciafemeninayritual}

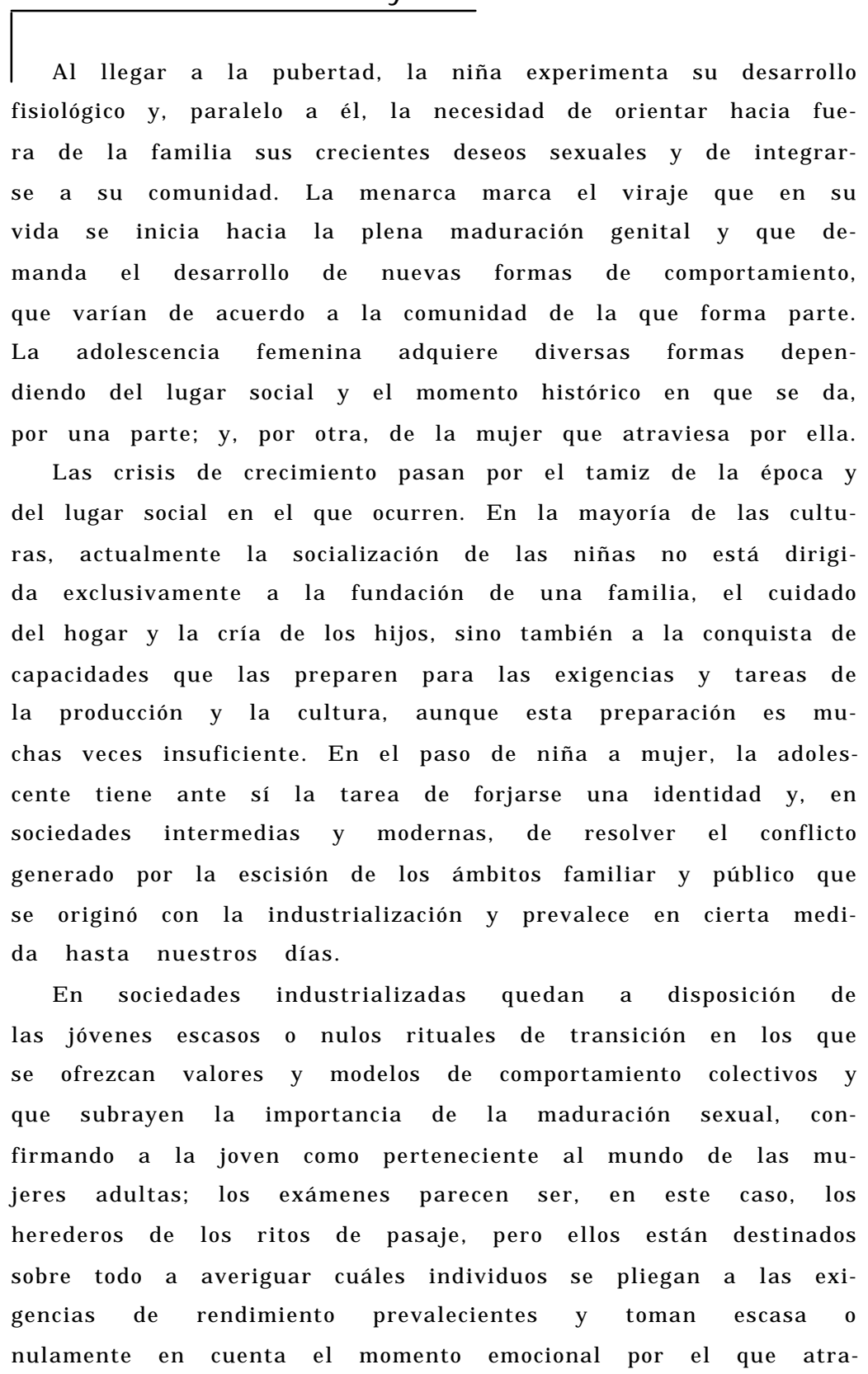




\section{Adolescencia femenina yritual}

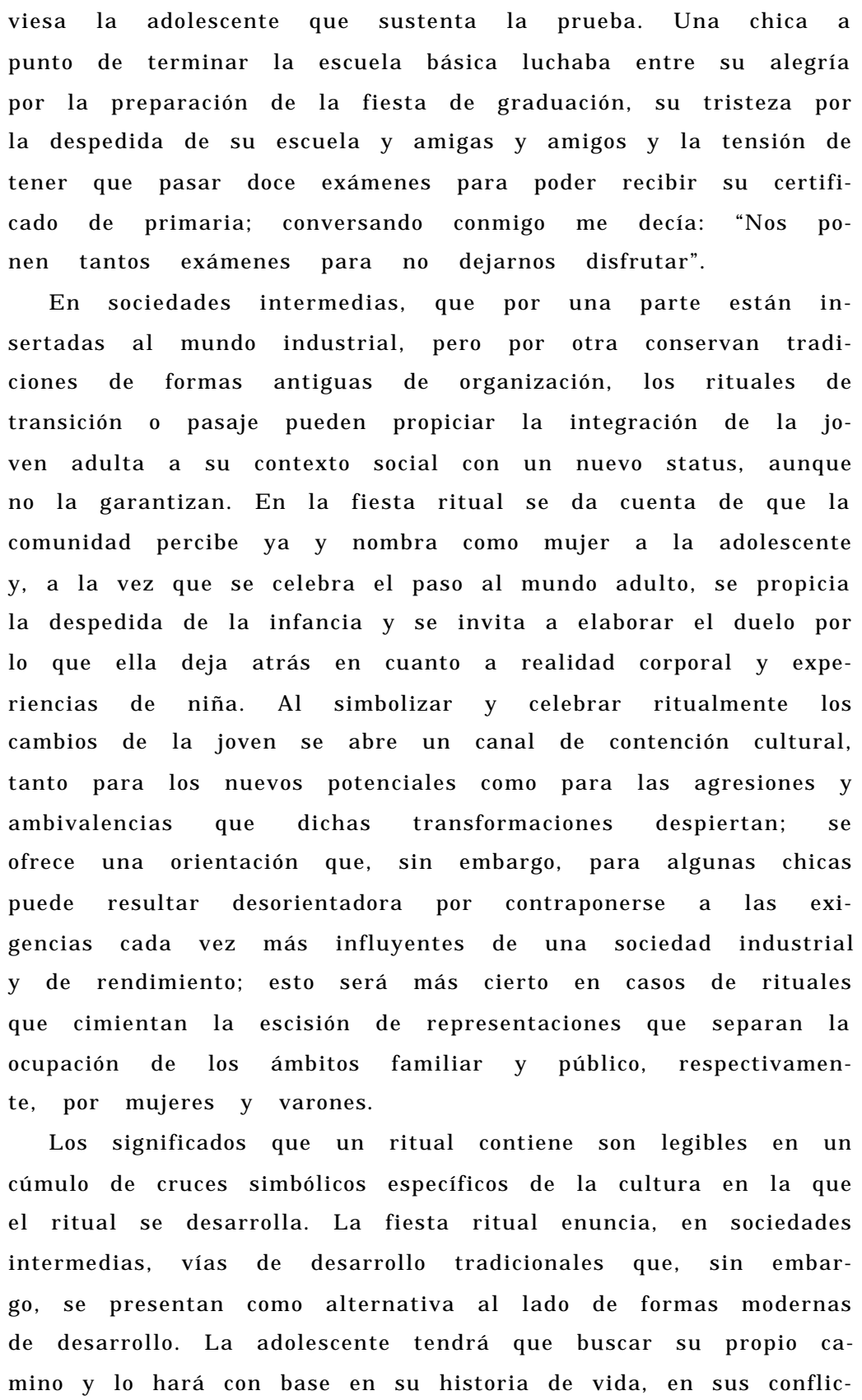




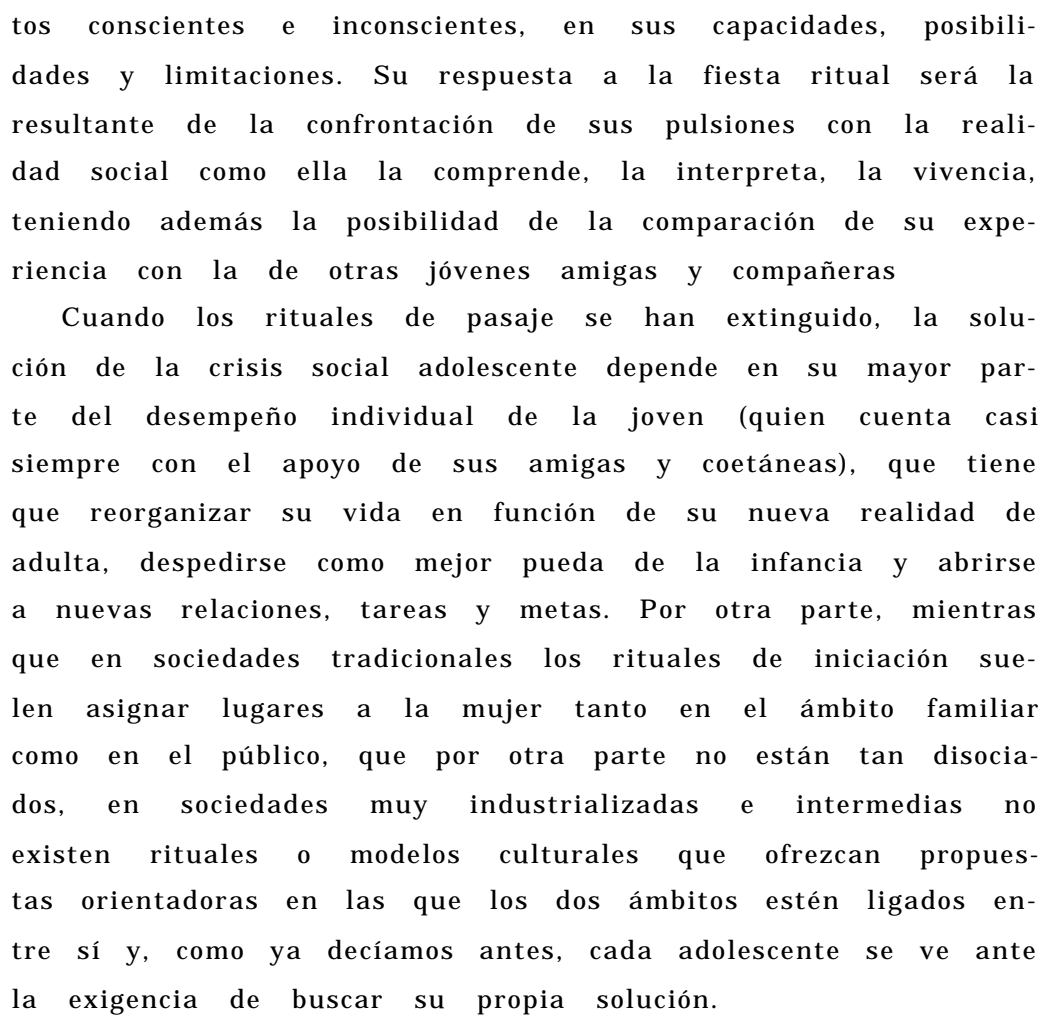

\section{La fiesta de los quince años} en algunas comunidades en México

A fin de volver más plástico el papel que desempeñan los rituales de pasaje en sociedades intermedias expondré a continuación lo observado por mí en la celebración de una tal fiesta y lo comentado por un grupo de chicas con las que realicé conversaciones con orientación psicoanalítica.

\section{Los quince años de Elvira}

Elvira vive en un pequeño poblado aledaño a la ciudad de Guadalajara, por lo que su vida transcurre entre estas dos 


\section{Adolescencia femeninay ritual}

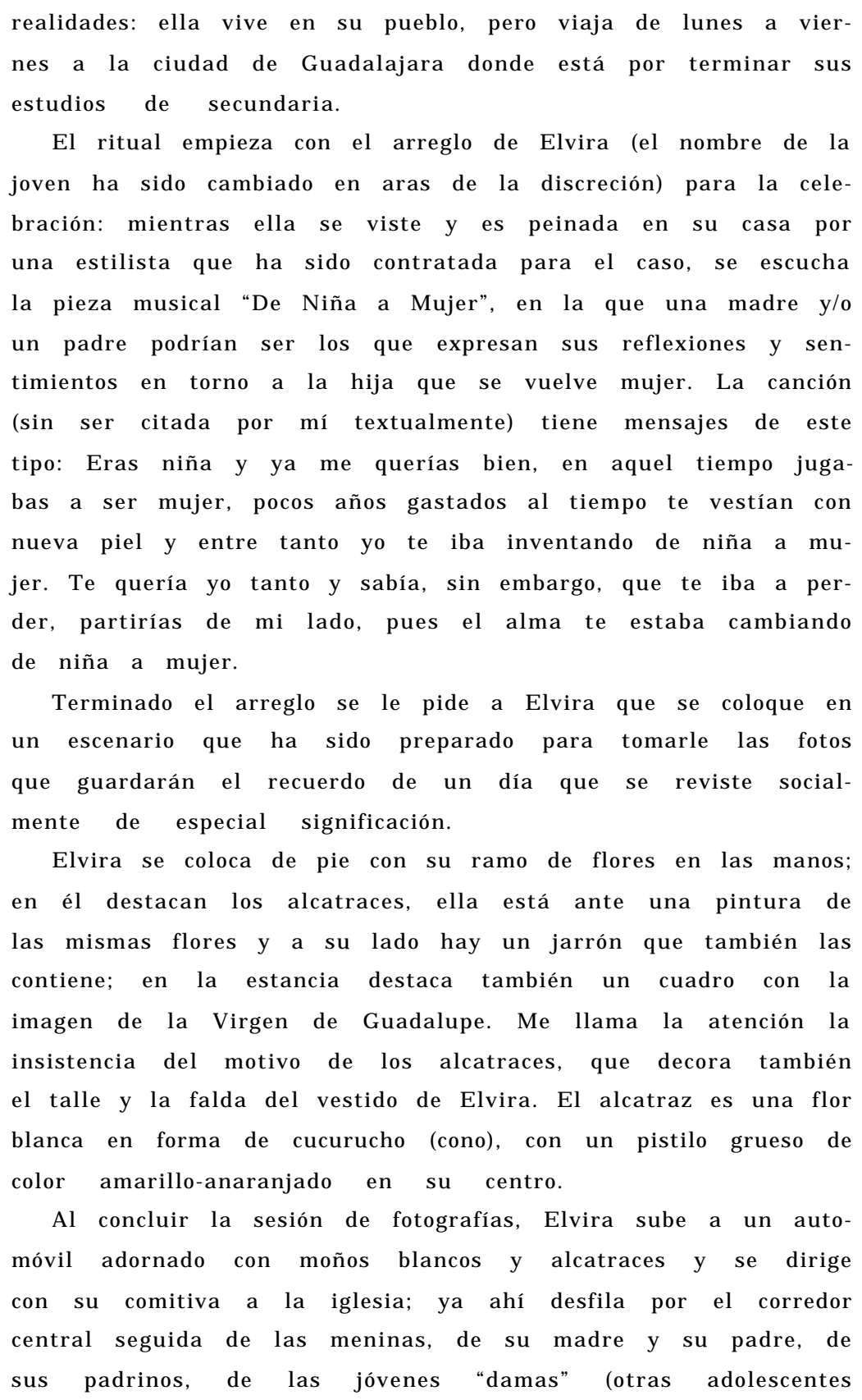

Elvira se coloca de pie con su ramo de flores en las manos; en él destacan los alcatraces, ella está ante una pintura de las mismas flores y a su lado hay un jarrón que también las contiene; en la estancia destaca también un cuadro con la imagen de la Virgen de Guadalupe. Me Ilama la atención la insistencia del motivo de los alcatraces, que decora también el talle y la falda del vestido de Elvira. El alcatraz es una flor blanca en forma de cucurucho (cono), con un pistilo grueso de color amarillo-anaranjado en su centro.

Al concluir la sesión de fotografías, Elvira sube a un automóvil adornado con moños blancos y alcatraces y se dirige con su comitiva a la iglesia; ya ahí desfila por el corredor central seguida de las meninas, de su madre y su padre, de sus padrinos, de las jóvenes "damas" (otras adolescentes 
amigas de la quinceañera) que portan artículos diversos para la celebración: cojín para el reclinatorio, libro de oraciones, licorera y copa para el brindis, ramo que se entregará a la quinceañera para que salga con él después de haber depositado el de flores naturales en el altar y finalmente de sus chambelanes. Elvira se acomoda en el reclinatorio más cercano al altar, al que se acerca una de las jóvenes damas para colocar sobre él el cojín blanco en el que Elvira se arrodillará cuando el ritual así lo exija. La misa sigue sus pasos usuales con algunas variantes: Elvira recibe la comunión católica con la hostia, pero también (sólo ella de entre todos los presentes) bebiendo vino del cáliz; al final, el sacerdote solicita a todos los asistentes un aplauso para la quinceañera y luego ella sube al altar a depositar su ramo, recibiendo enseguida de la dama correspondiente el ramo con el que saldrá. Ella permanece junto al altar, a donde se acercan uno a uno todos los integrantes de su comitiva para hacerse fotografiar con ella.

Ya fuera de la iglesia, Elvira se coloca en medio de sus chambelanes, que parecen más ocupados en desempeñar bien el papel que socialmente se les ha asignado que en admirar a la quinceañera; un grupo de jóvenes toca la guitarra y canta "las mañanitas", la típica canción mexicana para los cumpleaños. Elvira luce realmente preciosa, su ánimo parece apacible y tiene un aspecto muy juvenil, pero de mujer que ha dejado atrás la infancia. Terminada la canción, Elvira recibe abrazos de felicitación y una porra y sube al automóvil adornado para ser llevada al salón en el que tendrá lugar el baile.

En el salón, cada mesa está cubierta con un mantel blanco y tiene en el centro una vela adornada con moños del mismo color; Elvira, acompañada de una mujer vestida de negro que parece tener una relación muy cercana a ella, pero que no es su madre ni su madrina, toma una gran bolsa que contiene cestos cubiertos de encajes blancos y empieza a distri- 


\section{Adolescencia femenina yritual}

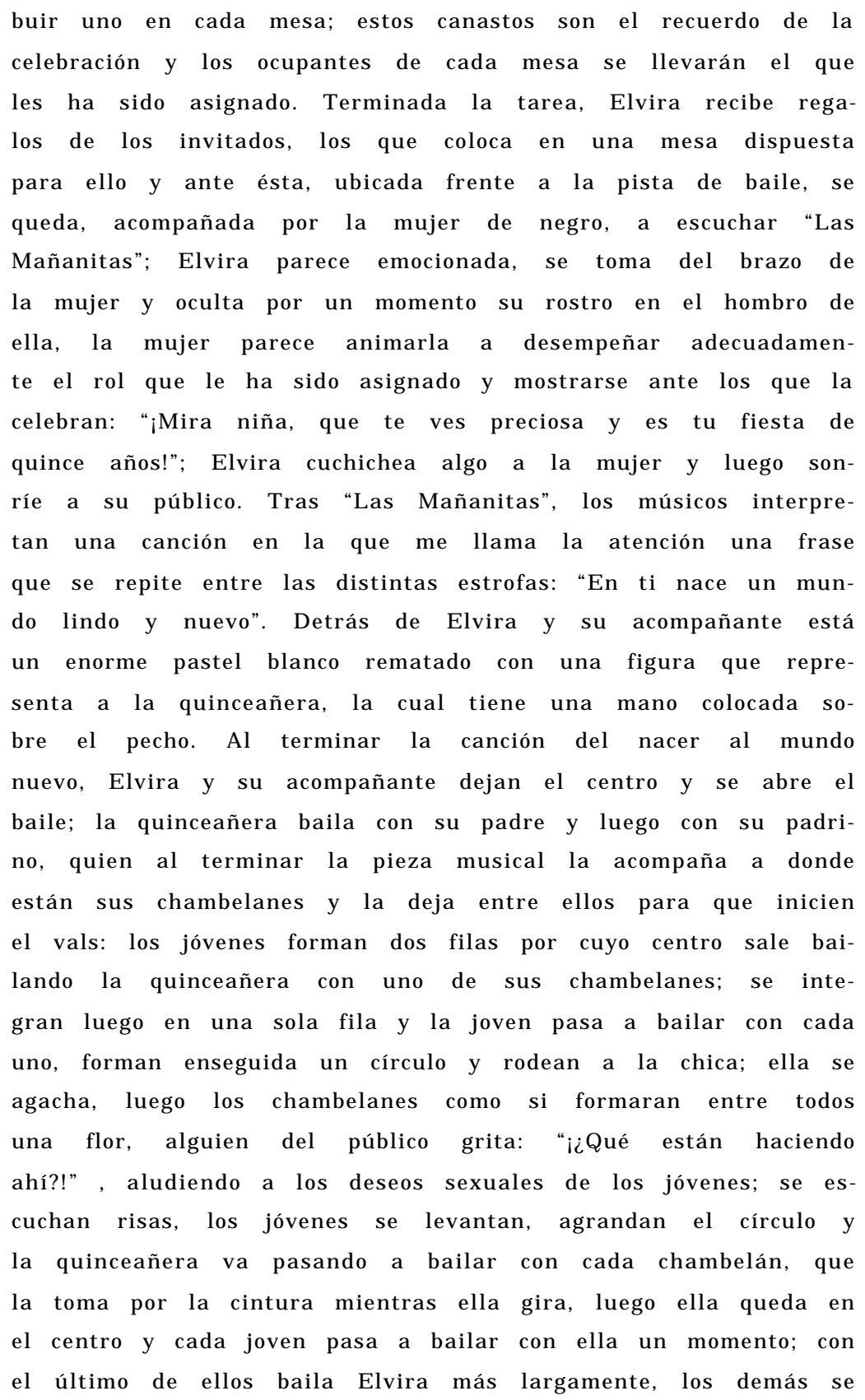


alinean y la pareja pasa al centro de ellos; en esta formación son invitados a brindar, para Elvira es su primer brindis oficial y recibe una copa especialmente adornada, los jóvenes una con un adorno más discreto y los invitados una sin ornato; todos brindan a la salud de la quinceañera y el padre de ella declara que ha sido presentada en sociedad, luego se abre el baile a todo el público; los jóvenes solteros invitados bailarán uno a uno con Elvira para quedar luego cada uno en libertad de elegir a la pareja que mejor le plazca. El último gesto oficial de Elvira es partir el pastel tras la cena, después los invitados empiezan a retirarse y la fiesta llega a su término.

\section{Reflexiones en tomo a la fiesta ritual}

Como rito que se celebra pasada la pubertad, la presenta-
ción de las mujeres quinceañeras en sociedad está en estre-
cha relación con su maduración sexual fisiológica. Aunque la
menarca (primera menstruación) es el índice del comienzo
de la fertilidad, en muchas sociedades el ritual de iniciación
femenino se celebra un año o dos después de tal aconteci-
miento, dando tiempo a que las jóvenes alcancen la madurez
de tal potencial; y aunque en la actualidad en sociedades in-
dustrializadas y en proceso de industrialización son menos
que en otras épocas las chicas que son madres a los quince
años, esta edad es socialmente marcada por la celebración
como la mínima para acceder a la maternidad sin enormes
riesgos físicos, psíquicos y sociales, como el momento en que
queda oficialmente permitido el cortejo de la chica por parte
de los jóvenes que la pretendan y que podrían coadyuvar a su
fecundación.
Siguiendo la reflexión en torno al desarrollo fisiológico de
las mujeres, los quince años parecen marcar para muchas de
ellas el punto en que son capaces de producir óvulos madu-
ros. La maduración fisiológica, que empezó a ser patente al-




\section{Adolescencia femenina yritual}

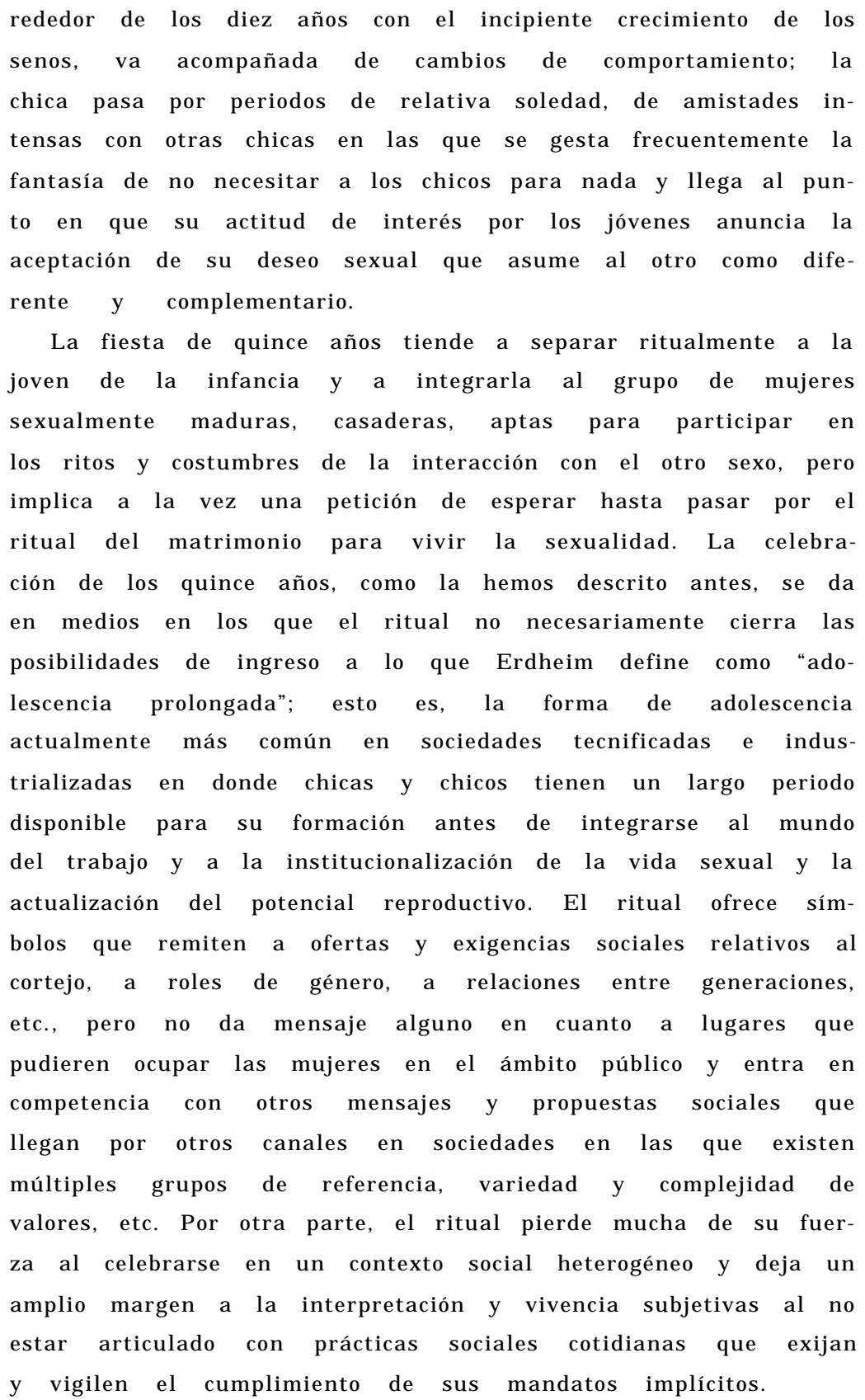

Sociedad $\$ No. 20 


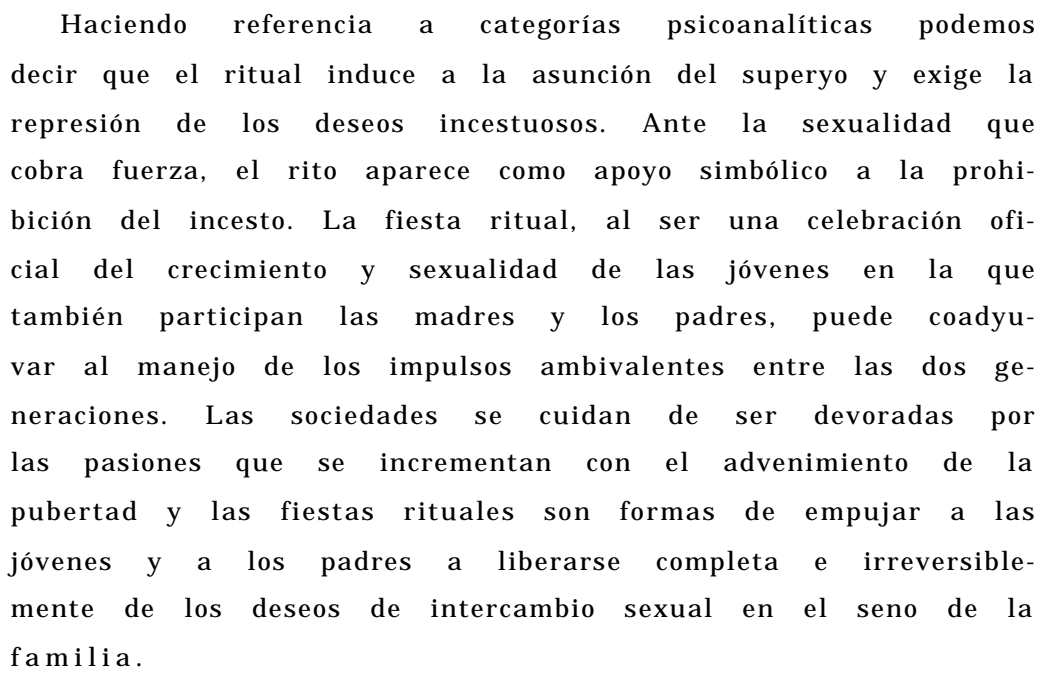

\section{Una conversación psicoanalítica contres quinceañeras}

La conversación que a continuación transcribo se dio en el
contexto de una serie de encuentros con cuatro chicas de una
preparatoria de la ciudad de Guadalajara, quienes estuvie-
ron dispuestas a participar en una investigación sobre ado-
lescencia femenina en diversos medios sociales; dichos
encuentros se dieron como espacios de la mayor libertad po-
sible para que las adolescentes hablaran de cualquier cosa
que desearan.
Mi metodología de trabajo en los encuentros con las chicas
fue cualitativa; los instrumentos de investigación fueron la
propia subjetividad, la comunicación de inconsciente a in-
consciente y el análisis de las interacciones y escenificacio-
nes, esto es, de las constelaciones sucesivas de transferencia
y contratransferencia que se dieron.
El par conceptual transferencia/contratransferencia tiene
su origen en el Psicoanálisis. La transferencia alude a la ten-
dencia a repetir, aunque con matices diversos y más o menos




\section{Adolescencia femenina yritual}

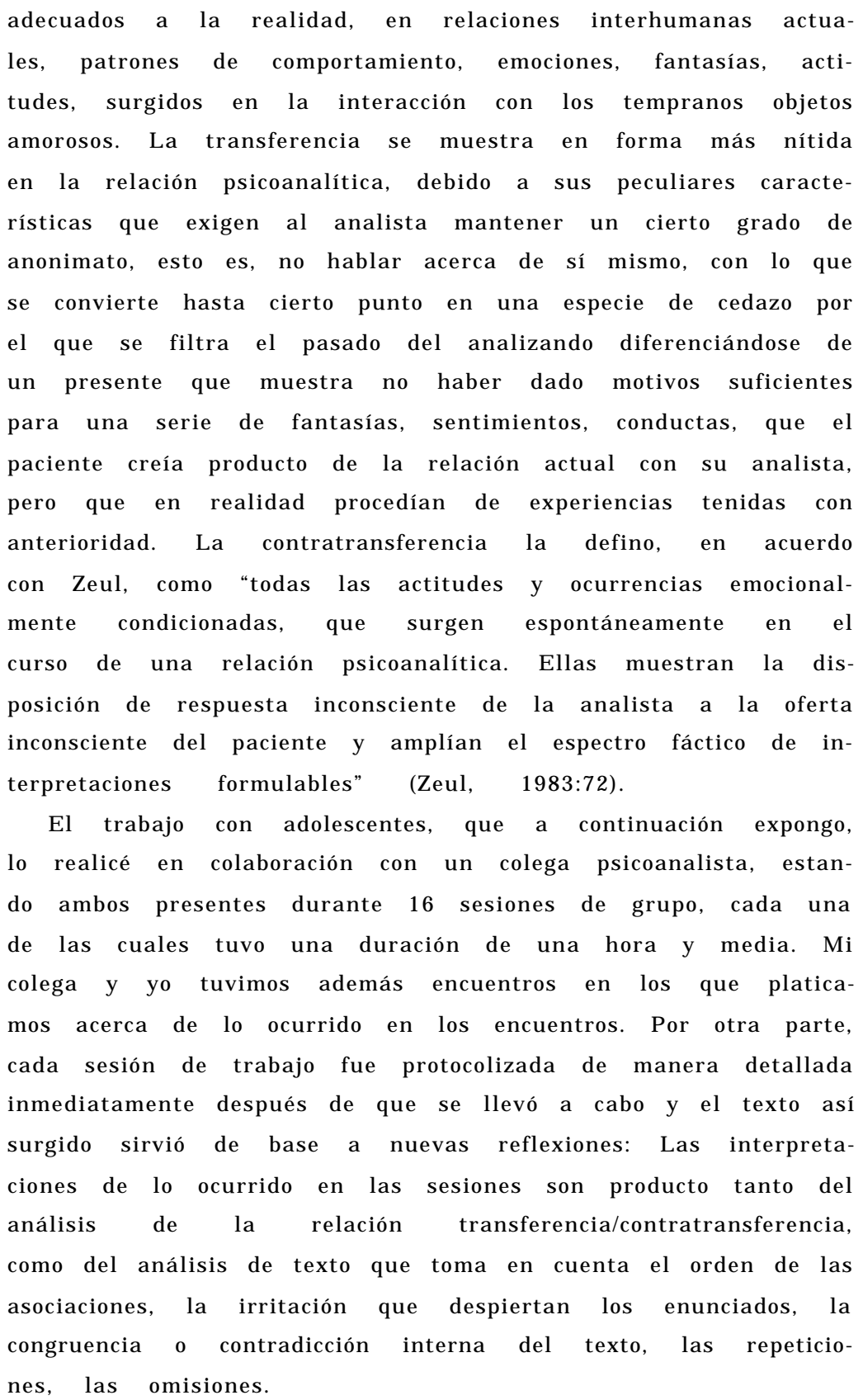




\section{Emma Ruiz Mart́n del Campo}

La sesión que aquí se describe fue el séptimo de nuestros encuentros y tiene relevancia para el presente trabajo porque en ella el tema fue la celebración de los quince años. Las cuatro chicas integrantes de este grupo tenían quince años en el periodo de nuestros encuentros (Abril los cumplió unos días antes de esta sesión).

A esta sesión asistieron Abril, Alejandra y Luciana (los nombres de las chicas fueron cambiados en aras de la discreción y ellas mismas, en una de las últimas sesiones, eligieron el nombre con el que deseaban sustituir el suyo verdadero en este documento). Fernanda nos hizo saber a través de Abril que no podría asistir a esta sesión.

Abril mencionó que el sábado anterior había celebrado su fiesta de quince años, preguntamos cómo le había ido y respondió entusiasmada: “¡Muy bien!”.

Miguel, mi colaborador en el trabajo con este grupo, preguntó qué significado podría tener el celebrar a las mujeres con una ceremonia especial en su 15으, cumpleaños. Abril dijo que su abuela le había explicado que era una forma de presentar en sociedad a la joven ahora casadera. Las chicas abundaron con placer en torno a diversos momentos de la fiesta; Luciana comentó que aunque Abril había llevado sólo cuatro chambelanes, muchas veces se llevan siete y lo más tradicional es que sean catorce, completando la quinceañera el número quince.

Abril explicó que primeramente se celebra una misa que es ofrecida por la del cumpleaños y tiene el significado de dar gracias a Dios y hacer una ofrenda por haberse convertido en mujer y sigue: "La quinceañera lleva un ramo para ser dejado en el altar y otro con el que ella se queda". Miguel pregunta cuál es el más bonito, Abril responde: "El de flores naturales, que es el que se ofrenda, a mí me parecía tan lindo que no quería dejarlo y le pregunté a mi mamá si podía poner sólo una flor sobre el altar y quedarme con el resto, pero ella me respondió indignada que ese ramo es para dejarse a Dios; 


\section{Adolescencia femenina yritual}

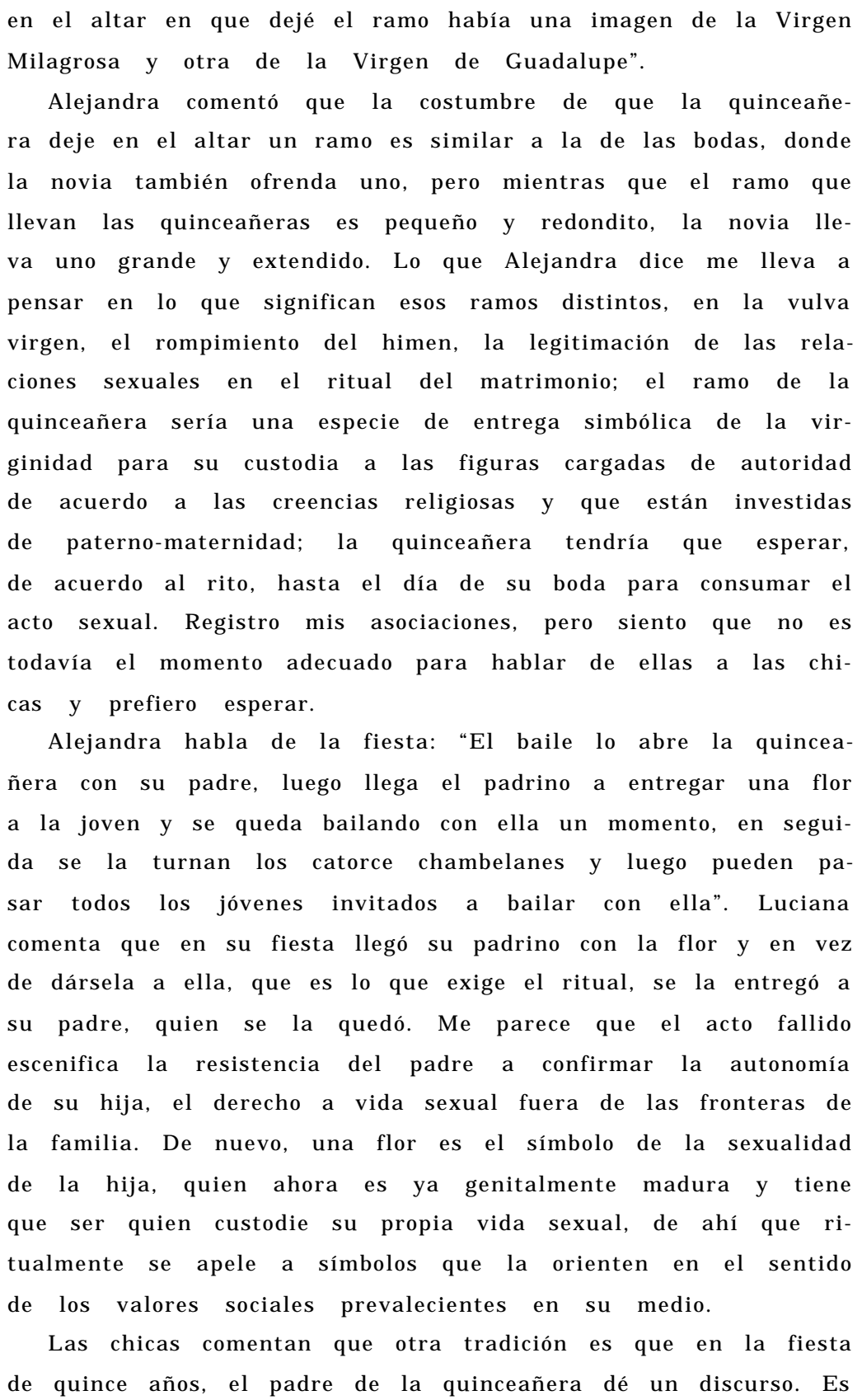


de nuevo Luciana quien habla de su experiencia. “Mi papá dijo: 'ésta es mi única princesa y ahora la presento en sociedad', luego agradeció la presencia de los asistentes y le pasó el micrófono a mi hermano, el que pidió que quien llegare a ser mi esposo fuera respetuoso conmigo, en seguida mi mamá agradeció a todos los asistentes y lo mismo hice yo; no me gustó lo que ellos dijeron, excepto el ser llamada 'princesa' por mi papá; de hecho, esa noche yo llevaba puesta una corona".

Ahora es Abril quien toma la palabra: "En la fiesta de los quince años se da también por vez primera a probar vino a la quinceañera, se le invita oficialmente a su primer brindis; a mí me dieron champaña y apenas si la probé, pues no me gustó, pero mi hermanita de doce años me preguntó si no la quería y si se la regalaba, le entregué la copa y ella la empinó hasta el fondo".

Luciana habla de otro acto simbólico: "La quinceañera, que lleva una muñeca en un momento dado de la fiesta, la avienta hacia atrás por encima de su hombro y una de las niñas que asisten a la fiesta la espera para atraparla y quedarse con ella. En mi fiesta esta costumbre se modificó un poco: pasaron una tras otra varias niñas a pedirme mi muñeca argumentando que yo era ya muy grande para jugar con ella, pero yo me resistía a entregarla, hasta que finalmente se la di a una de ellas".

Abril narra: “Cuando yo lancé la muñeca durante mi fiesta, se quedó atorada en la lámpara del salón y mi papá utilizó un gran palo para bajarla, cuando por fin cayó, la atrapó un señor que la escondió bajo su saco y no quiso entregarla y dado que por micrófono se pide que la pequeña que haya atrapado la muñeca pase a bailar con la quinceañera un baile típico mexicano, el señor tuvo que pasar a bailar conmigo el "jarabe tapatío", porque yo sé bailarlo; cuando lo vi acercarse pensé: ‘eso le pasa por no querer entregar la muñeca'".

Miguel preguntó si se les ocurría por qué a los varones no se les hace un festejo similar al de las chicas al cumplir quin- 


\section{Adolescencia femenina yritual}

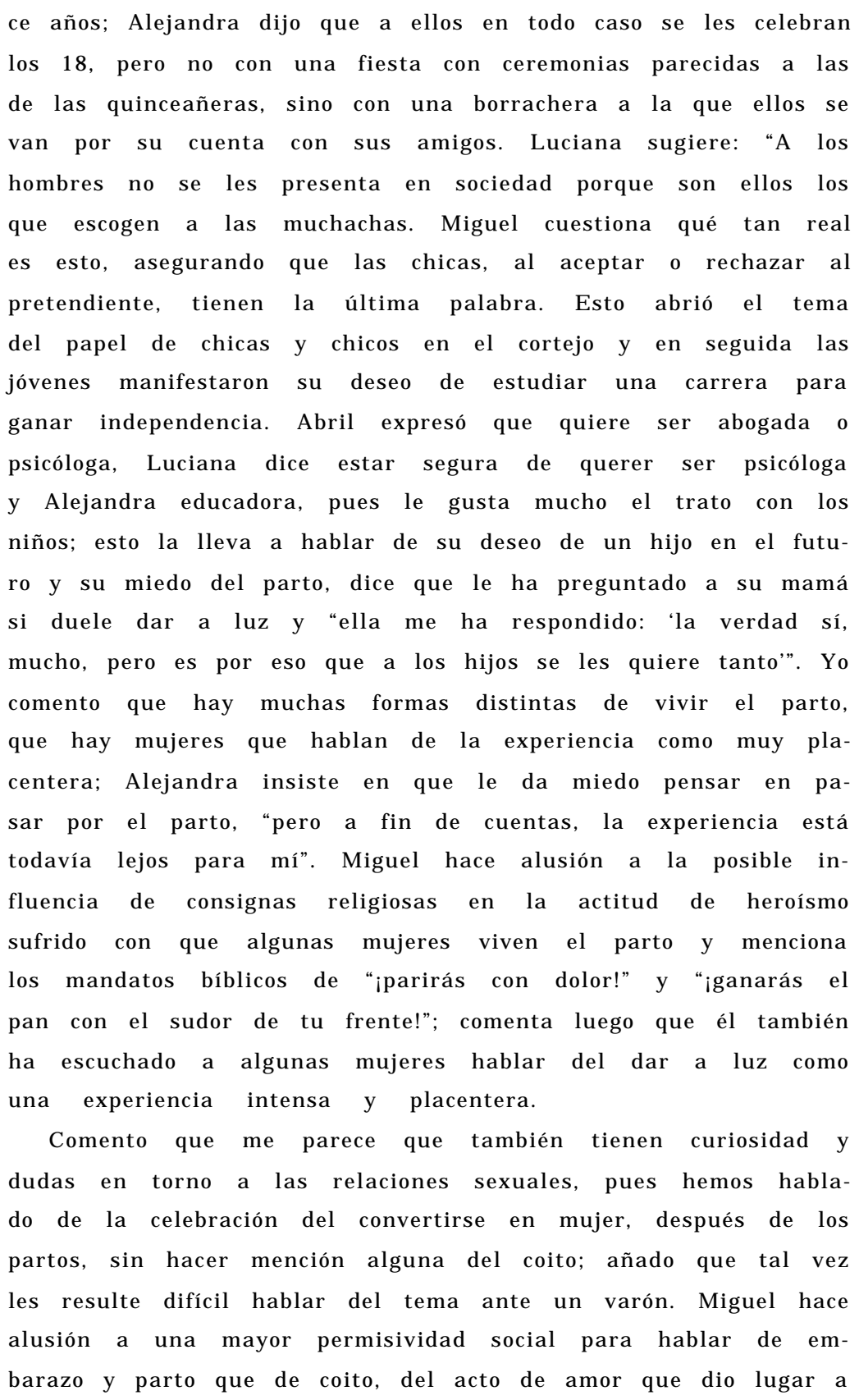


ellos. Luciana parece confirmar lo que dice Miguel y aborda el tema del embarazo comentando que una amiga de su edad quedó preñada fuera de matrimonio y el padre de ella quiere que aborte, pero no así la joven ni su madre; menciona también que el joven que embarazó a su amiga murió días después trágicamente en un accidente. Luciana continúa, dice que antes ella estaba de acuerdo en que si la mujer no deseaba al hijo que iba a tener lo abortara, pues pensaba que un hijo no deseado viene al mundo sólo a sufrir, pero que ya no piensa así desde que leyó un libro que describe cómo el feto es arrancado del vientre de su madre y destrozado por una especie de aspiradora que le jala primero un brazo, luego una pierna y así sucesivamente. Abril enfatiza: “¡Es una vida!". Alejandra por su parte dice: "Si yo fuera a tener un bebé pensaría que Dios me lo manda por algo y tendría que recibirlo con amor". Yo digo que se puede estar o no de acuerdo con el aborto, pero que ciertamente no es lo mismo un aborto en el caso de un embarazo avanzado que en las primeras semanas del mismo. Luciana asevera: "Lo cierto es que si no se quiere un embarazo hay muchas técnicas para evitarlo y habría que utilizarlas". Nos preguntamos qué puede significar el que, a pesar de estar enteradas del ciclo menstrual y los periodos de mayor fertilidad, de los métodos anticonceptivos, etc., muchas adolescentes resulten embarazadas; mencionamos que puede haber causas inconscientes para embarazarse, por ejemplo, entre muchas posibles, el deseo de retener a la pareja, comprobar que se pueden tener hijos, experimentar como más reales los órganos sexuales internos, sentimientos de culpa por estar teniendo relaciones sexuales que llevan a mostrar el efecto del "pecado", pero que de éste $u$ otros temas que ellas deseen podemos hablar en nuestro siguiente encuentro, pues el tiempo de esta sesión ha terminado.

Mis sensaciones en esta sesión fueron muy agradables, sentí a las chicas interesadas, motivadas; fuera de nuestro 
salón, en la escuela, todo parecía muy tranquilo. Estuvimos inmersos en lo nuestro, trabajamos creativa y placenteramente.

\section{Análisis dela conversación con tres quinceañeras}

\footnotetext{
Lo primero que quedó patente por el entusiasmo e interés con que las chicas abordaron el tema de la fiesta de quince años es que esta ceremonia les gusta y haber pasado por ella fue para todas y cada una de gran significación.

Ante la cuestión del significado de la fiesta ritual, las chicas apelan primeramente al conocimiento que de la tradición tienen mujeres de generaciones anteriores a la suya: “Mi abuela me ha explicado que es una forma de presentar en sociedad a la joven ahora casadera"; luego pasan a expresar sus vivencias, sensaciones y reflexiones en torno a la fiesta. Abril narra cómo se permitió solicitar a la madre modificar el rito para poder quedarse con el ramo de flores naturales que le parecía tan lindo y asienta la respuesta de la madre: "Me respondió indignada que ese ramo es para dejarse a Dios" y la asociación inmediata de Abril es: “En el altar en que dejé el ramo había una imagen de la Virgen Milagrosa y otra de la Virgen de Guadalupe". El ramo, símbolo de la virginidad, es puesto bajo la custodia de "un padre y una madre" internalizados en los que se cree y que están investidos de autoridad: el Dios padre y la Virgen madre. Ahora los padres reales no podrán estar tan presentes en la vida de la niña convertida en mujer y se apela a lo simbólico para promover cierto orden social en torno a la vida sexual.

Alejandra compara espontáneamente el ramo de la quinceañera con el de la novia; el primero, "pequeño y redondito", alude a la virgen genitalidad; el de la novia, "grande y extendido", remite a la apertura explícita al varón, al otro y a la relación sexual que es socialmente consagrada con el matri-
} 


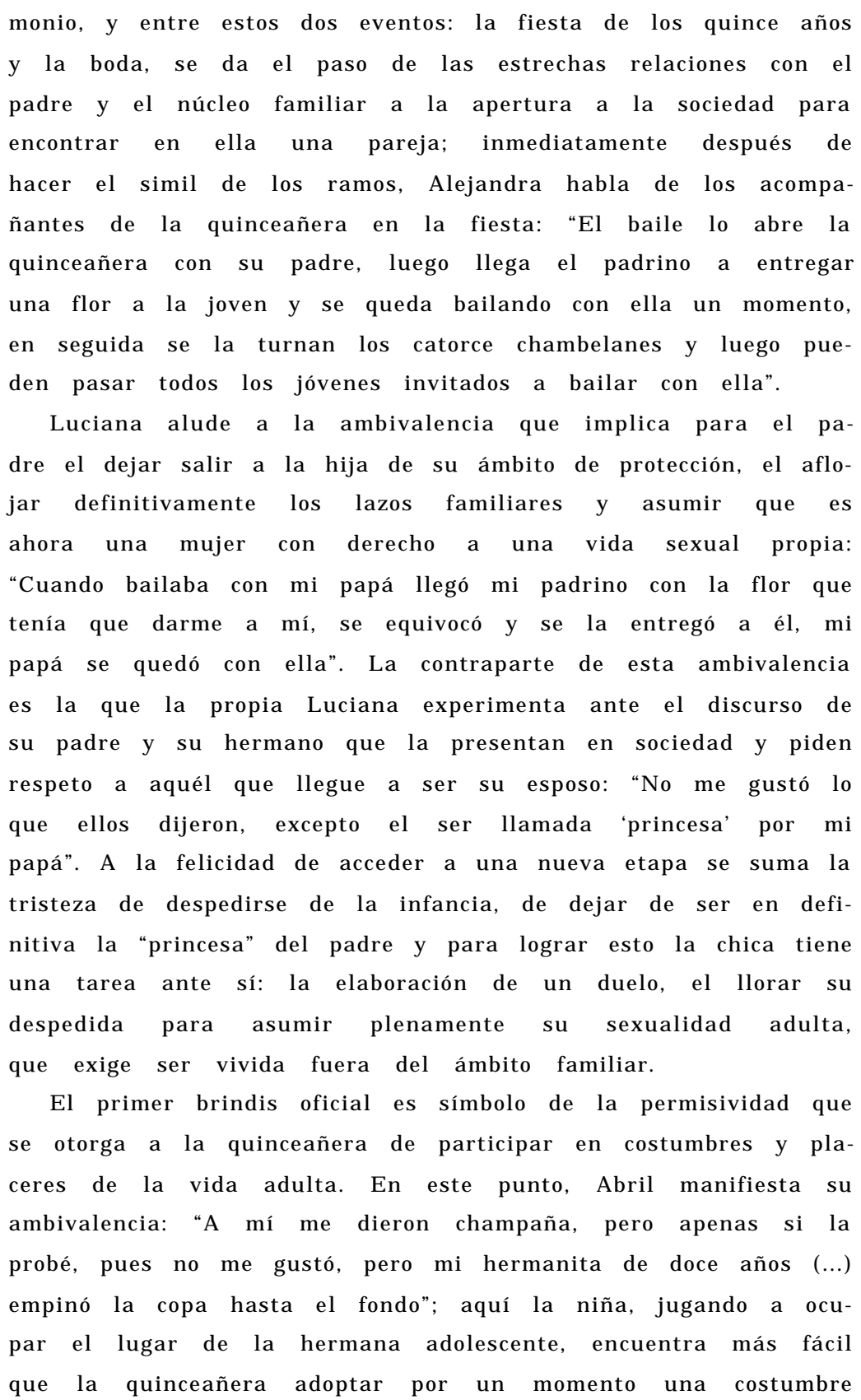




\section{Adolescencia femenina yritual}

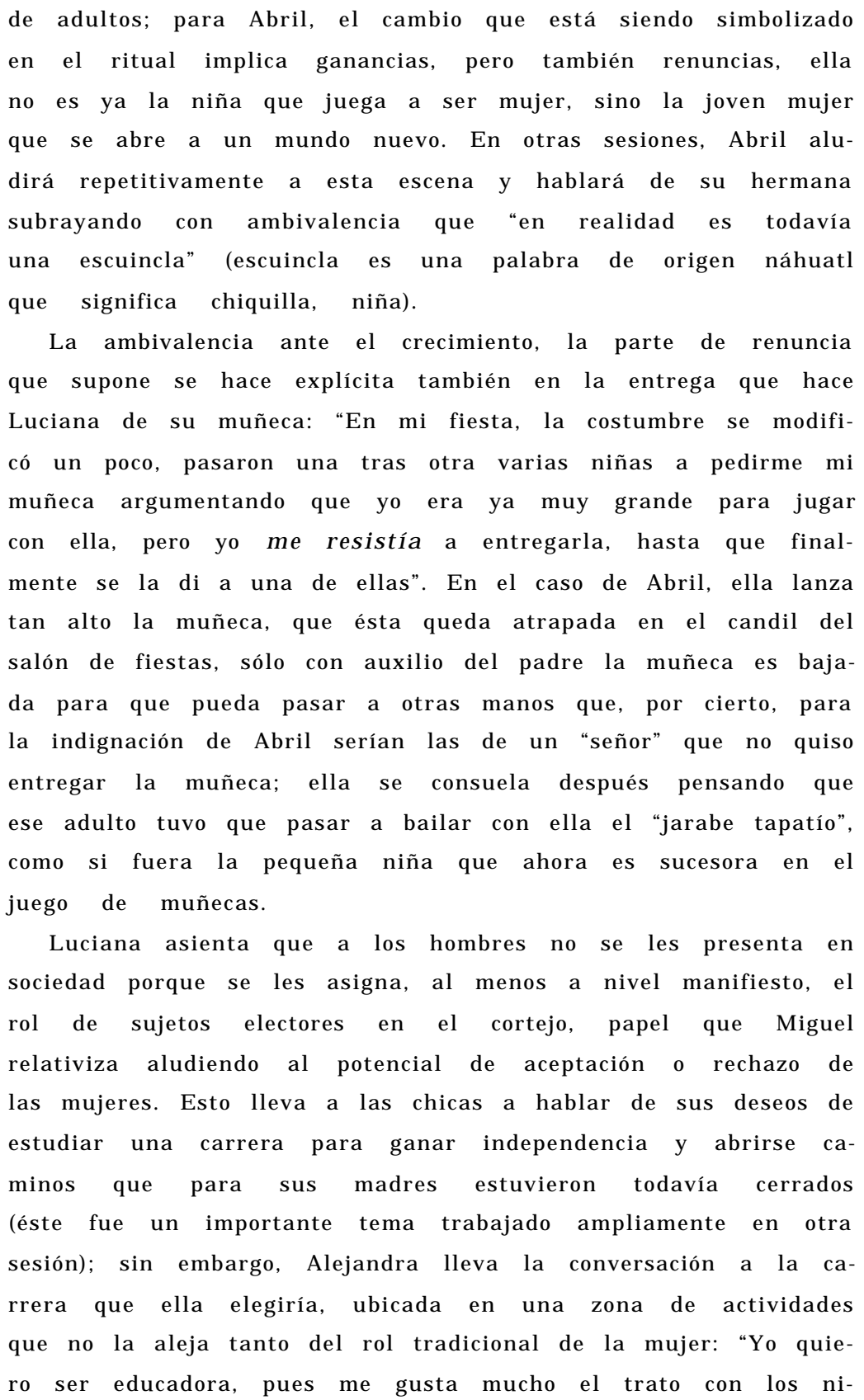

La ambivalencia ante el crecimiento, la parte de renuncia que supone se hace explícita también en la entrega que hace Luciana de su muñeca: "En mi fiesta, la costumbre se modificó un poco, pasaron una tras otra varias niñas a pedirme mi muñeca argumentando que yo era ya muy grande para jugar con ella, pero yo me resistía a entregarla, hasta que finalmente se la di a una de ellas". En el caso de Abril, ella lanza tan alto la muñeca, que ésta queda atrapada en el candil del salón de fiestas, sólo con auxilio del padre la muñeca es bajada para que pueda pasar a otras manos que, por cierto, para la indignación de Abril serían las de un "señor" que no quiso entregar la muñeca; ella se consuela después pensando que ese adulto tuvo que pasar a bailar con ella el "jarabe tapatío", como si fuera la pequeña niña que ahora es sucesora en el juego de muñecas.

Luciana asienta que a los hombres no se les presenta en sociedad porque se les asigna, al menos a nivel manifiesto, el rol de sujetos electores en el cortejo, papel que Miguel relativiza aludiendo al potencial de aceptación o rechazo de las mujeres. Esto lleva a las chicas a hablar de sus deseos de estudiar una carrera para ganar independencia y abrirse caminos que para sus madres estuvieron todavía cerrados (éste fue un importante tema trabajado ampliamente en otra sesión); sin embargo, Alejandra lleva la conversación a la carrera que ella elegiría, ubicada en una zona de actividades que no la aleja tanto del rol tradicional de la mujer: "Yo quiero ser educadora, pues me gusta mucho el trato con los ni-

Sociedad $\bigotimes$ No. 20 


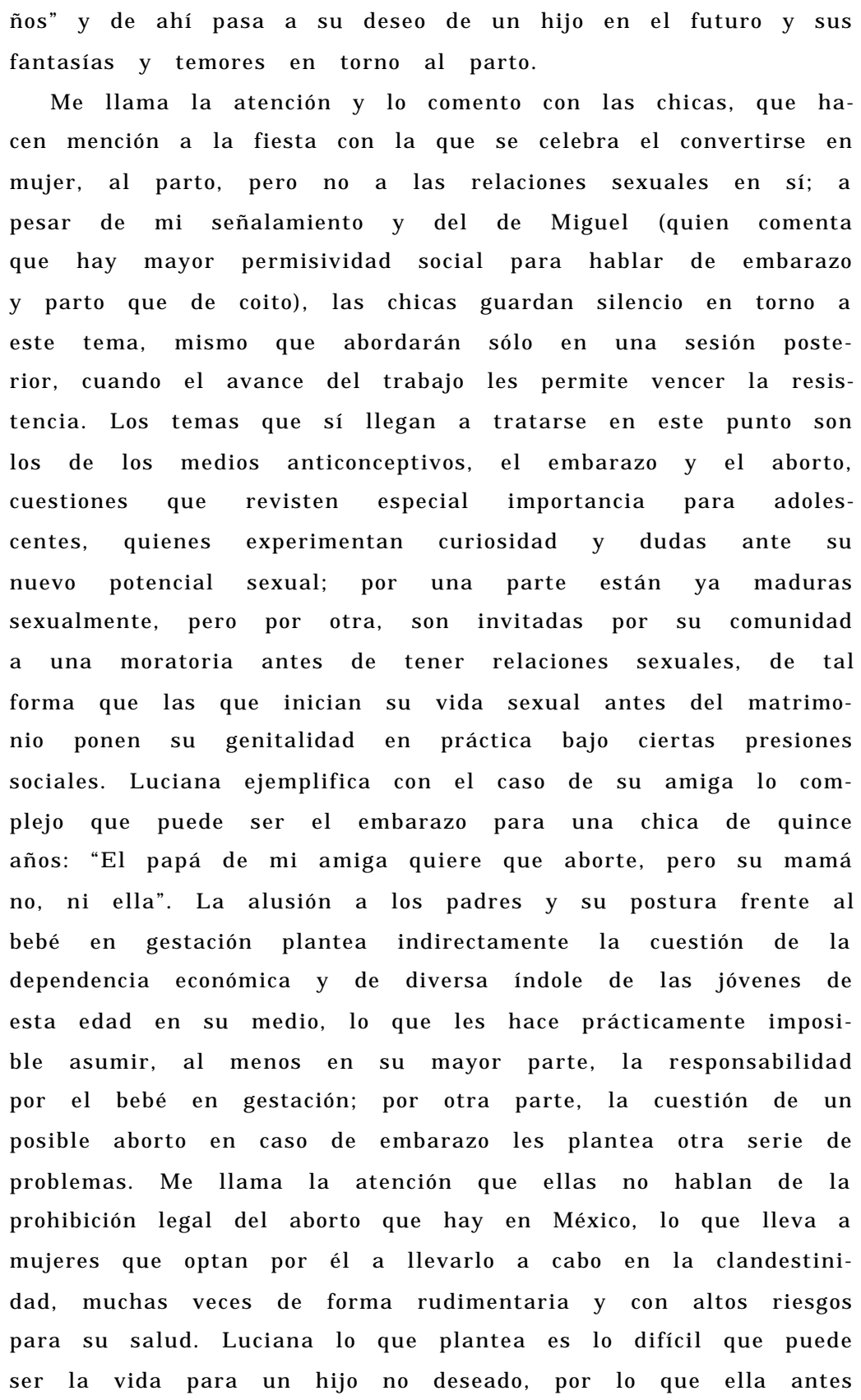




\section{Adolescencia femenina yritual}

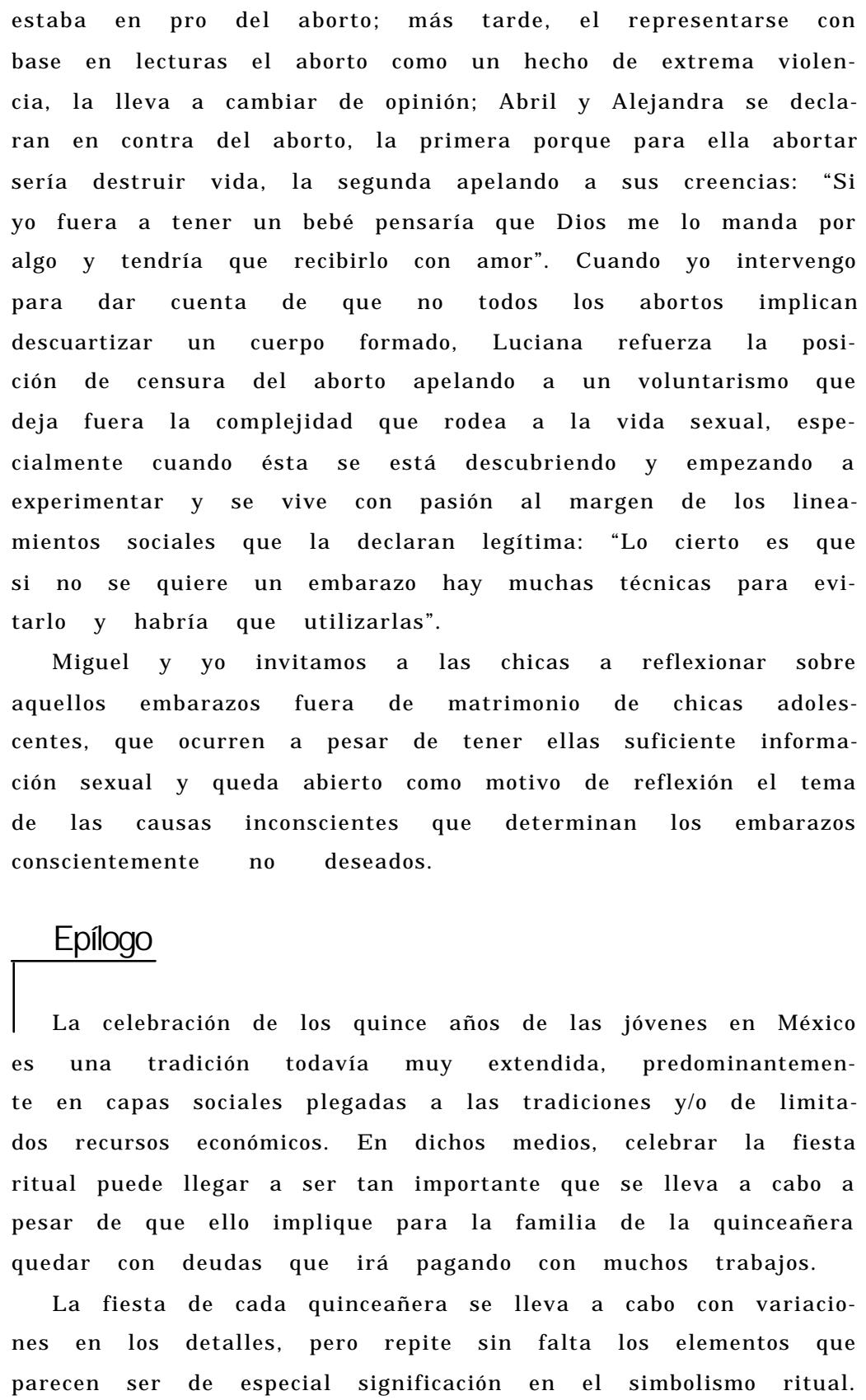

\section{Epílogo}

La celebración de los quince años de las jóvenes en México es una tradición todavía muy extendida, predominantemente en capas sociales plegadas a las tradiciones y/o de limitados recursos económicos. En dichos medios, celebrar la fiesta ritual puede llegar a ser tan importante que se lleva a cabo a pesar de que ello implique para la familia de la quinceañera quedar con deudas que irá pagando con muchos trabajos.

La fiesta de cada quinceañera se lleva a cabo con variaciones en los detalles, pero repite sin falta los elementos que parecen ser de especial significación en el simbolismo ritual. 


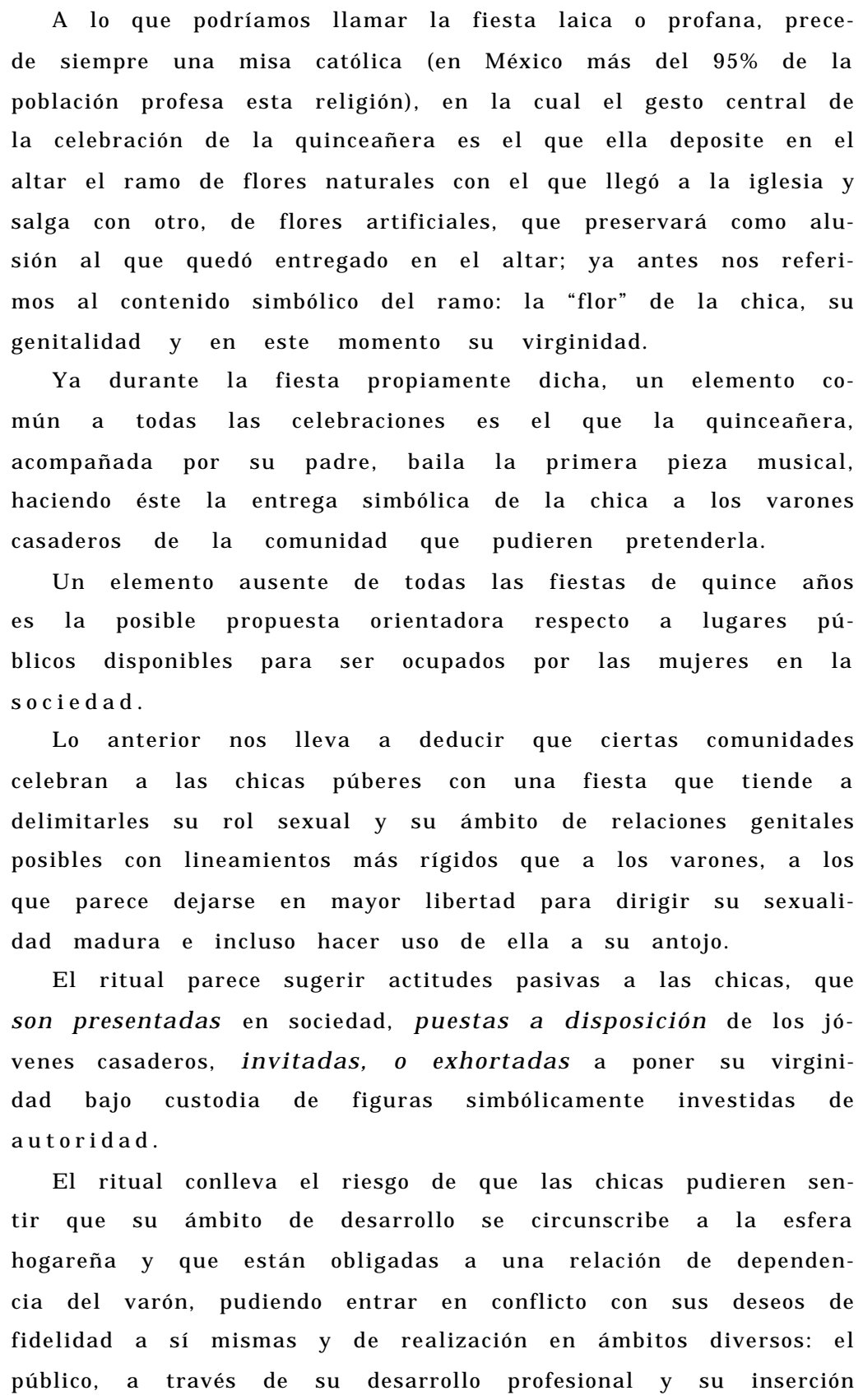

El ritual parece sugerir actitudes pasivas a las chicas, que son presentadas en sociedad, puestas a disposición de los jóvenes casaderos, invitadas, o exhortadas a poner su virginidad bajo custodia de figuras simbólicamente investidas de autoridad.

El ritual conlleva el riesgo de que las chicas pudieren sentir que su ámbito de desarrollo se circunscribe a la esfera hogareña y que están obligadas a una relación de dependencia del varón, pudiendo entrar en conflicto con sus deseos de fidelidad a sí mismas y de realización en ámbitos diversos: el público, a través de su desarrollo profesional y su inserción 


\section{Adolescencia femeninay ritual}

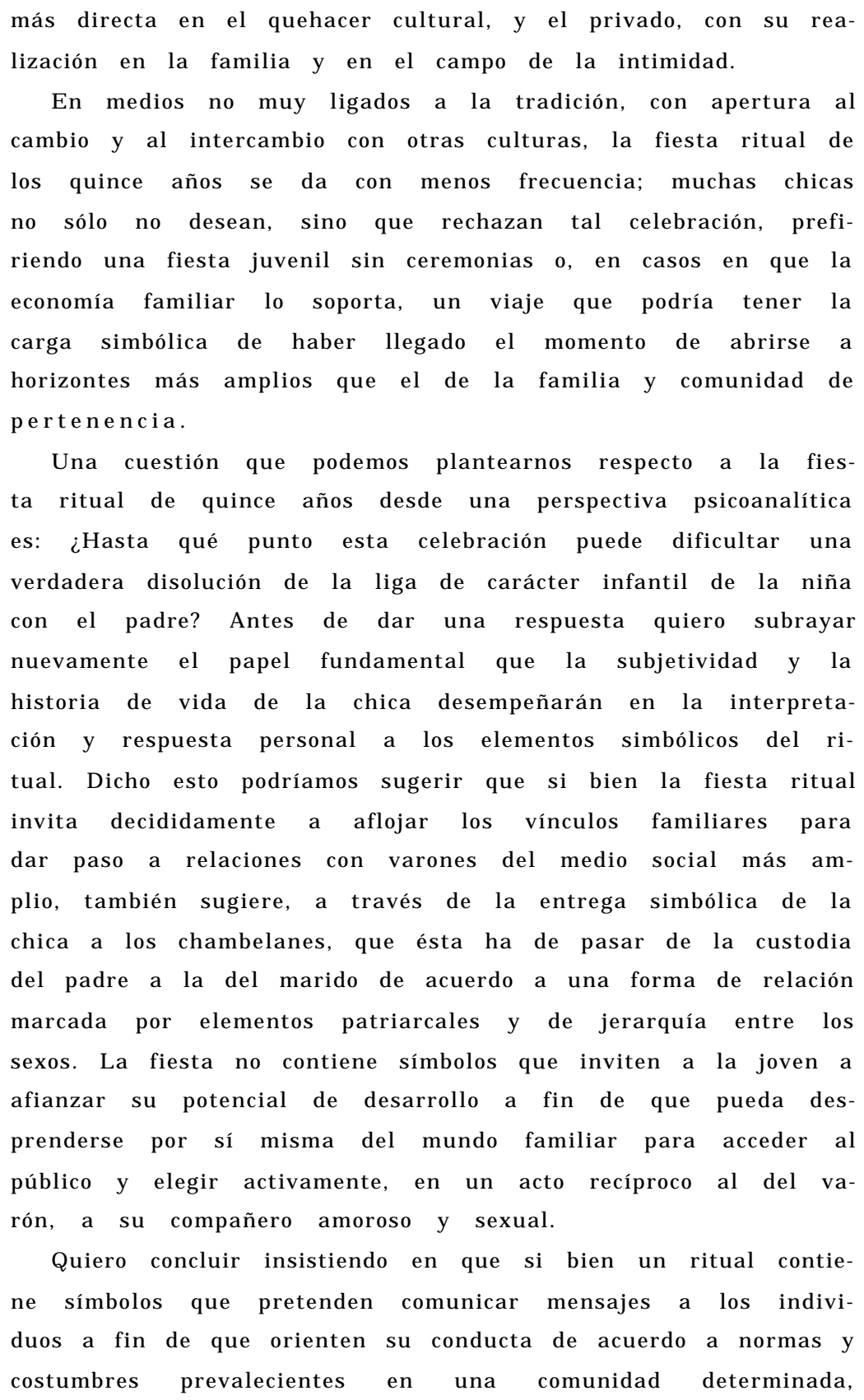




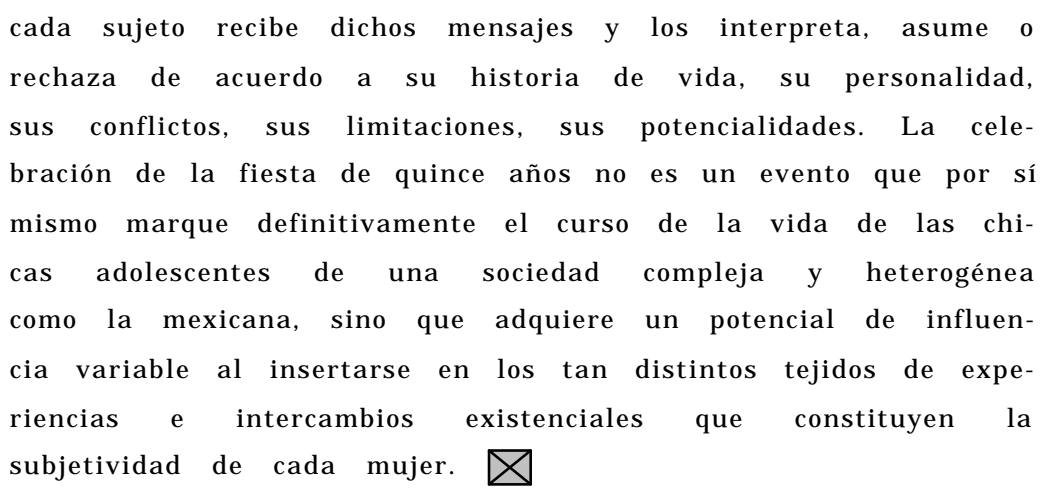

Bibliografía Erdheim, Mario (1992). "Die gesellschaftliche Produktion von Unbewusstheit"'(La Producción Social de Inconsciencia), Editorial Suhrkamp, Frankfurt, Alemania.

Freud, Sigmund (1930). 'Das Unbehagen in der Cultur'(EI Malestar en la Cultura), Studienausgabe, tomo XI, Editorial Fischer, Frankfurt, Alemania.

- (1905). "Drei Abhandllungen zur Sexualtheorie"(Tres Ensayos para una Teoría Sexual), Studienausgabe, tomo V, Editorial Fischer, Frankfurt, Alemania.

Kaplan, Louise (1994). “Abschied von derKindheit”'(Despedida de la Infancia), Editorial Klett-Cotta, Stuttgart, Alemania.

Lévi-Strauss, C. (1972). “'Primitive' und 'Zivilisierte"'(“Primitivos”y "Civilizados", Zünich, Suiza.

Waldeck, Ruth (1998). 'Die Fesseln derFrau. Zur Psychoanalyse der weiblichen Adoleszenz" (Las Cadenas de la Mujer. Sobreel Psicoanálisis de la Adolescencia Femenina). En: Zeitzschrittür Sexualforschung (Revista para la Investigación de la Sexualidad), J hi 11, Frankfurt, Alemania.

Zeul, Mechthild (1983). "Gegenübertragung - ein Stiefkind der Psychoanalyse" (Contratransferencia - un Hijastro del Psicoanálisis). En: 'Das Unbehagen in der Psychoanalyse"(EI Malestar enel Psicoanálisis), Editorial Qumran, FrankfurtyPańs. 